\title{
A Comprehensive Assessment Method for Safety Risk of Gas Tunnel Construction Based on Fuzzy Bayesian Network
}

\author{
Daohong Qiu, Cong Qu, Yiguo Xue*, Binghua Zhou, Xin Li, Xinmin Ma, Jiuhua Cui \\ Geotechnical and Structural Engineering Research Center, Shandong University, Jinan 250061, China
}

Received: 7 November 2019

Accepted: 28 December 2019

\begin{abstract}
Currently, gas disasters in tunnels occur frequently and cause severe casualties and property losses. However, there are few studies on the risk assessment of gas tunnels, especially comprehensive analysis of the safety risk of gas tunnels considering multiple factors. This paper presents a comprehensive assessment method for safety risk of gas tunnel construction based on fuzzy Bayesian network. The results of safety risk assessment are determined by two aspects: risk probability and risk hazard. In the process of assessment, 12 risk indicators were extracted from 32 important factors by the principal component analysis method, and a fuzzy interpretative structural modeling was established and converted into a fuzzy Bayesian network to evaluate the risk probability. The risk index weight was obtained through principal component analysis, and the risk hazard level was calculated by using the fuzzy comprehensive assessment method in combination with the hazard degree of the risk index. After a comprehensive assessment of gas concentration and other field conditions, the relevant parameters such as the fuzzy interpretative structural modeling and fuzzy Bayesian network are determined. This paper selects two construction segments of the Like tunnel as case studies to verify the feasibility and application prospects of this method. The method establishes a safety risk assessment model for gas tunnels, which can allow management personnel to fully evaluate gas tunnel risk and provides a safe construction environment.
\end{abstract}

Keywords: gas tunnel, risk analysis, principal component analysis, fuzzy interpretative structural modeling, fuzzy Bayesian network

\section{Introduction}

In recent years, a number of tunnels have experienced severe gas accidents during their construction in China and the world [1-2]. In the mountainous area of

*e-mail: xieagle@sdu.edu.cn southwest China, the gas occurrence area is widely distributed [3]. There are differences in the geological conditions, construction, and management of tunnels and coal mines. Therefore, the gas problem should be of concern and valued during tunnel construction. Doyle [4] believed that there is not enough information to avoid the potential risks of underground engineering gas disasters in many years ago. Until now, there have 
been few studies on the risk of tunnel gas disasters. Gas explosion safety accidents in these tunnels have become a construction safety problem of great concern to the public.

Kuang [5] put forward a suitable classification method for railway gas tunnels, airflow, the gas concentration and other indexes are considered. Additionally, non-gas factors should be considered in the research process. Many accidents are related to environmental and management factors of tunnel construction. A method of assessing the risk value of unsafe behavior was proposed based on the analysis of unsafe behavior of humans in underground coal mines [6]. Zhang [7] used a fuzzy analytic hierarchy process to determine the weights of evaluation indexes and attempted to establish an assessment system for evaluating the risk of gas outburst in tunnels in noncoal formations in the survey phase of tunneling. A fuzzy analytic hierarchy process was used to estimate and rank all of these factors to develop a management model and guide safety managers in the mining process [8]. Bayesian networks can be used to solve the practical problems based on the case [9-12]. Conditional probability tables have been established by expert investigation with fuzzy Bayesian networks [13-14]. In addition, some assessment methods are applied during the mine gas disaster research process [15-18]. The causes of gas tunnel disasters are not only natural factors, but also human factors, and the management level is critical to ensure the safe construction of gas tunnels. In addition, in the process of risk assessment, the final risk level of a gas tunnel needs to consider the quantification of disaster accidents after the occurrence of risks, including combustion, suffocation, and explosion.

The research on the disaster risk of projects dates back to the early 1980s [19-20]. Risk analysis and decision-making procedures are being applied to large engineering projects with increasing frequency [21]. Risk assessment during tunnel construction is an important part of tunnel risk management [2225 ]. Fuzzy set theory can be effectively applied in the method of safety risk assessment [26]. Probabilistic risk analysis is probably the most widely used approach for risk assessment in rock engineering and geotechnical engineering more broadly [27]. A large number of important risk factors and hazards in tunnels have been identified. However, an effective overall idea about the risk management concept is still missing [28]. Risk assessment involves a large number of influencing factors. If the comprehensiveness and accuracy of the influencing factors are insufficient, the assessment model of the gas tunnel will be adversely affected. Based on collecting a large number of influencing factors, principal component analysis is adopted to extract the key risk indicators to ensure the integrity of information. In the absence of objective sample data, it is feasible to use the expert scoring method to construct a Bayesian network for risk assessment.
Additionally, the current research on the risk assessment of gas tunnels does not consider the comprehensiveness and complexity. Different from other research methods, this paper adopts multifactor fuzzy comprehensive evaluation method. This paper uses a principal component analysis method to analyze many influential factors. From two aspects of risk probability and risk of gas tunnel hazard, a fuzzy Bayesian network is used to calculate the risk probability, and the risk hazard value is obtained by using a fuzzy comprehensive evaluation method. Two construction segments of the Like tunnel are selected as case studies to establish a scientific risk assessment system for gas tunnel construction.

\section{Study Area}

The Like tunnel is one of the tunnels used for reconstructing the energy expansion project of the Emei to Miyi section of the Chengdu-Kunming railway (Fig. 1). The tunnel is $5976 \mathrm{~m}$ long, with a single hole and two lines, and the maximum buried depth is approximately $712 \mathrm{~m}$. The tunnel is located in the area of the Hengduan mid-alpine landscape, with terrain fluctuations. The tunnel mainly passes through three sets of strata, including sandstone, shale sandwiched mudstone and coal line, mudstone sandwiched sandstone and mountain Emei basalt and contains 2 faults and 1 synclinal structure. Groundwater mainly consists of bedrock fissure water. The tunnel is constructed by drilling and blasting. Large sections of the tunnel pass through coal-bearing line strata and are designed and constructed according to a low-gas tunnel.

(1) Bad geological condition

The lithological of DK282+342 DK $282+442$ and DK288+240 340 is Jurassic purple-red mudstone sandwiched sandstone, Triassic gray sandstone, shale sandwiched mudstone and coal seam. DK282+423 DK283+460 and DK286+430 DK288+340 are located in coal-bearing strata with two layers of thickness of $0.25 \sim 0.45 \mathrm{~m}$ at the bottom, belonging to the gas weathering zone.

\section{(2) Construction method}

The sections of DK282+421 427 and DK288+364 397 are constructed by the clear excavation method, and the remaining sections are organized according to the principle of NATM. The excavation method uses the bench method, smooth blasting, and initial support of the bolt and shotcrete net. In the initial support process, the steel mesh and steel arch frame construction are welded together, which puts forward higher requirements for fire management.

\section{(3) Gas management}

Gas management systems mainly include gas tunnel fire prevention and explosion prevention management systems, tunnel ventilation management systems, tunnel instruments and equipment management systems, gas tunnel hot fire management systems, gas tunnel 


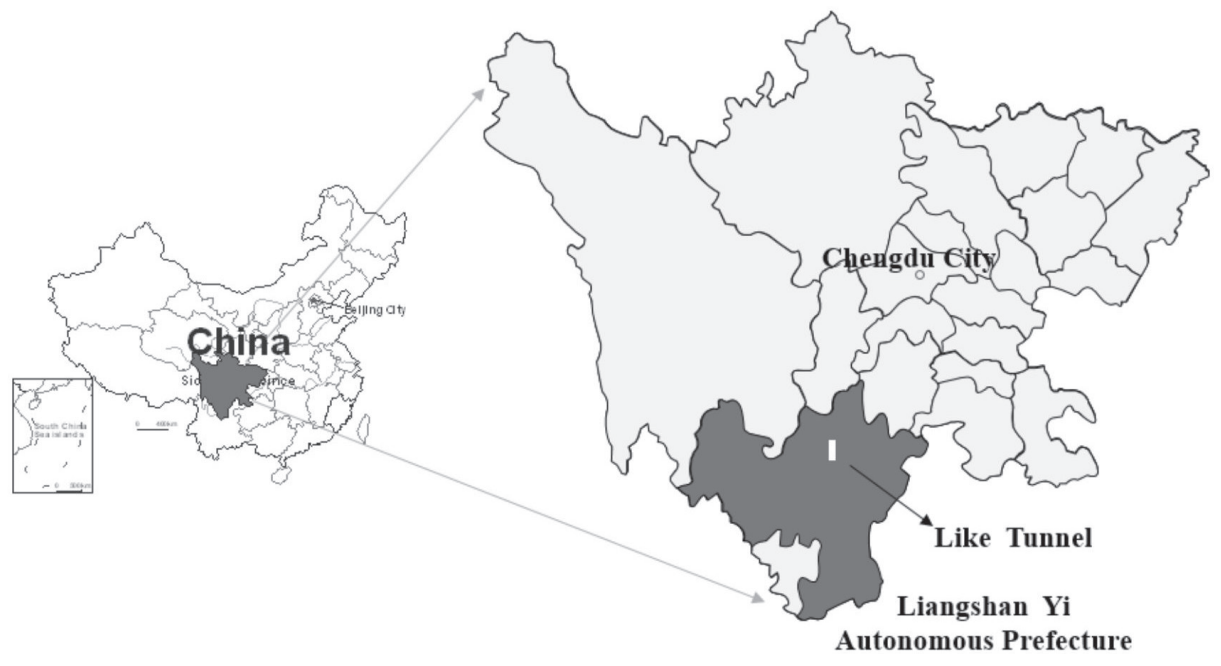

Fig. 1. Study area of the gas tunnel.

blasting and drilling safety management regulations. The system of "one blasting and three detections" must be implemented in the excavation and blasting of the tunnel. "one blasting and three detections" is the detection of the gas concentration before and after the blasting of the tunnel face, including detection before installing explosives, detection before the blasting and detection after the blasting. The air volume and pressure must meet the design requirements.

In this paper, two construction sections of the Like tunnel are selected as case studies for analysis. They are: segment $\# 1$ and segment \#2, and the mileage is DK283+103.6 DK283 +203.6 and DK283+250 DK283+350, respectively. The two segments are located in coal-bearing strata; the seam thickness in the two segments is different; the rocks in the crossing area of the segments are mainly sandstone sandwiched shale; fractures are more developed; there is water in the rock strata of these two construction segments.

Segment \#1: The construction unit did not make adequate preparations for the phenomenon of gas escaping and did not take reasonable measures to dilute the gas concentration in time. The tile inspection department does not pay attention to gas detection, and equipment calibration is not timely.

Segment \#2: The construction unit has made full preparations for the phenomenon of gas escaping and formulated and implemented reasonable gas control methods to dilute the gas concentration. The tile inspection department strengthens gas detection, and timely equipment calibration occurs.

\section{Methodology}

\section{Principal Component Analysis}

Principal component analysis (PCA) [29-30] is a statistical analysis method based on a covariance matrix or correlation coefficient matrix that integrates data from multiple indicators, extracts information related to research purposes, and classifies the original multiple variables into a few comprehensive indicators. The main steps of principal component analysis are as follows:

(1) Suppose that the evaluation object $X$ has $s$ important influencing factors and $m$ characteristic indicators to form a matrix of order $s \times m$.

$$
X=\left(x_{i j}\right)_{s m}
$$

...where $x_{i j}$ is the $j$ th indicator of the $i$ th important factor.

(2) Standardize the raw data.

$$
y_{i j}=\frac{x_{i j}-\bar{x}_{i j}}{S_{j}}
$$

...where $S_{j}$ is the standard deviation of the $j$ th indicator and $\bar{x}_{j}$ is the mean of the jth indicator.

The normalized matrix is:

$$
Y=\left(y_{i j}\right)_{s m}
$$

(3) The correlation coefficient matrix among the evaluation indexes is calculated as follows:

$$
R=\frac{1}{s-1} Y^{T} Y
$$

(4) The eigenvalues and eigenvectors are calculated, and the principal components are determined by selecting appropriate principles.

\section{Fuzzy Interpretative Structural Modeling}

Interpretative structural modeling (ISM) [31] is mainly used to analyze the relationship among a large number of elements in a complex system and 
express it in the form of a multilevel hierarchical structure. This method expresses the complicated relationship among system-related factors into a multi-order structural model using mathematical reasoning.

In fuzzy set theory [32], each element in a fuzzy set can take any real number between 0 and 1. Supposing the universe is $X, \tilde{A}$ is a map of $X$ to $[0,1] ; \tilde{A}: X \rightarrow[0,1]$, $x \rightarrow \tilde{A}(x)$. This triangular fuzzy number is expressed as $\tilde{A}=(a, b, c)$, and the membership functions are as follows:

$$
\tilde{A}(x)=\left\{\begin{array}{l}
0, x<a \\
\frac{x-a}{b-a}, a \leq x \leq b \\
\frac{c-x}{c-b}, b<x<c \\
0, x>c
\end{array}\right.
$$

This paper introduces seven natural language variables [33], which are very low, low, medium, high, high, and very high. All the above natural language variables can be converted into corresponding triangular fuzzy numbers (Table 1).

Membership functions of natural language variables and triangular fuzzy numbers are shown in Fig. 2.

The modeling steps of fuzzy interpretative structural modeling (FISM) are as follows:

(1) Identify the relevant factors that can be used to document analyses, questionnaire surveys, etc.

(2) Analyze the correlation among the factors, and generate the adjacency matrix.

$$
\begin{gathered}
A=\left(a_{i j}\right)_{n \times n} \\
a_{i j}=\left\{\begin{array}{l}
1, F_{i} M F_{j} \\
0, F_{i} \bar{M} F_{j}
\end{array}\right.
\end{gathered}
$$

Table 1. The corresponding relationship between natural language variables and triangular fuzzy numbers.

\begin{tabular}{|c|c|}
\hline Natural language variables & Triangular fuzzy number \\
\hline Very low (VL) & $(0,0,0.1)$ \\
\hline Low (L) & $(0,0.1,0.3)$ \\
\hline Few low (FL) & $(0.1,0.3,0.5)$ \\
\hline Medium (M) & $(0.3,0.5,0.7)$ \\
\hline Few high (FH) & $(0.5,0.7,0.9)$ \\
\hline High (H) & $(0.7,0.9,1)$ \\
\hline Very low (VH) & $(0.9,1,1)$ \\
\hline
\end{tabular}

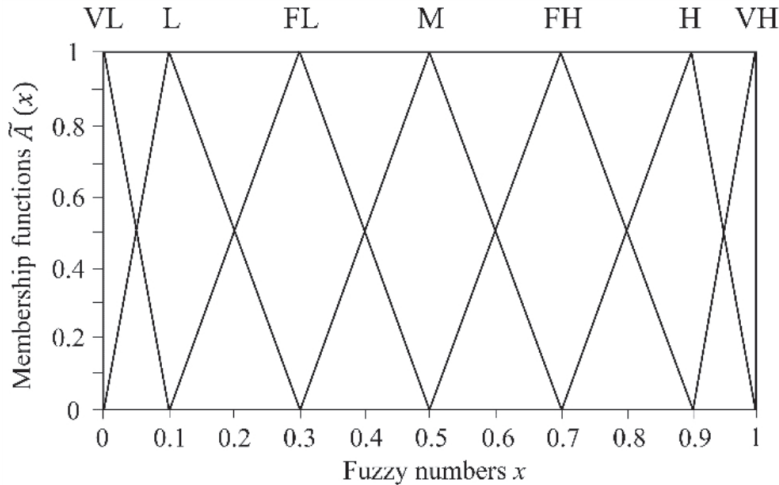

Fig. 2. Membership functions of natural language variables and triangular fuzzy numbers.

...where $M$ is factor $F_{i}$ that has a direct impact on factor $F_{j}$ and $\bar{M}$ is factor $F_{i}$ that has no direct effect on factor $F_{j}$.

(3) Find the accessible matrix. Suppose $A_{1}=A+I$, where $I$ is the identity matrix; exponentiation and Boolean algebra are successively performed on matrix $A_{1}$.

$$
R=\left(A_{1}\right)^{1} \neq\left(A_{1}\right)^{2} \neq\left(A_{1}\right)^{3} \neq \ldots \neq\left(A_{1}\right)^{\lambda}=\left(A_{1}\right)^{\lambda+1}
$$

(4) A hierarchical division of the accessible matrix is carried out. All the sets of elements that can be reached from factor $i$ are defined as accessible sets of $i$.

$$
R S\left(F_{i}\right)=\left\{F_{j} \mid F_{j} \in F, r_{i j}=1\right\}
$$

All the element sets that reach element $i$ are defined as the antecedent set of element $i$.

$$
A S\left(F_{i}\right)=\left\{F_{j} \mid F_{j} \in F, r_{j i}=1\right\}
$$

Determine the intersection of the reachable set and antecedent set.

$$
I S\left(F_{i}\right)=R S\left(F_{i}\right) \cap A S\left(F_{i}\right)
$$

If the reachable set of an element is the same as the intersection, the element belongs to level 1. Repeat the above steps to find the intersections among the remaining elements except for the level 1 elements, compare them with the reachable set, and determine the other levels until all the element levels are determined.

$$
L_{i}=\left\{F_{j} \mid F_{j} \in F-L_{0}-\ldots-L_{i-1}, I S\left(F_{i}\right)=R S\left(F_{i}\right)\right\}
$$

...where $R S\left(F_{i}\right)$ is the reachable set of factor $F_{i} ; A S\left(F_{i}\right)$ is the antecedent set of factor $F_{i}$; IS $\left(F_{i}\right)$ is the intersection of the reachable and antecedent sets of factor $F_{i} ; L_{i}$ is layer $i$; and $i=1,2, \ldots, l ; l \leq n ; L_{0}=\varnothing$. 
(5) Interpretative structural modeling and fuzzy theory are combined [34], and the FISM model is established.

\section{Fuzzy Bayesian Networks}

The Bayes formula is a very useful tool for calculating the posterior probability [35]. For a Bayesian network (BN) [36] based on the Bayesian formula, the expression form of the Bayesian formula is:

$$
P(A \mid B)=\frac{P(B \mid A) P(A)}{P(B)}
$$

...where $P(A)$ is the prior probability and $P(A)>0, P(A \mid B)$ is the posterior probability, and $P(B \mid A)$ is the likelihood rate.

Probabilistic graphical models and decision graphs are modeling tools for reasoning and decision making under uncertainty [37]. Bayesian decision theory provides a reasonable framework for representing and reasoning with decision problems under uncertainty [38]. A BN consists of a directed acyclic graph (DAG) and conditional probability distribution table (CPT).

Suppose there are BN nodes $x_{i}, x_{j}(i \neq j, 1 \leq i \leq n, 1 \leq j \leq m)$. If there is a directional edge from $x_{i}$ to $x_{i}$, then $x_{i}$ is the parent of $x_{j}$, and $x_{j}$ is the child of $x_{i}$. All the parent nodes of $x_{j}$ are represented by the set $E\left(x_{i}\right)$. Each node in the $\mathrm{BN}$ corresponds to a conditional probability distribution table. The edge probability of the parent node $x_{i}$ is $P\left(x_{i}\right)$, and the conditional probability distribution of other intermediate nodes $x_{j}$ is $P\left(x_{j} \mid E\left(x_{j}\right)\right)$.

The calculation formula of the $\mathrm{BN}$ joint probability distribution function is:

$$
\begin{aligned}
P\left(x_{1}, x_{2}, \ldots x_{n}\right) & =\prod P\left(x_{i} \mid x_{i-1}, x_{i-2}, \ldots x_{1}\right) \\
& =\prod P\left(x_{i} \mid E\left(x_{i}\right)\right)
\end{aligned}
$$

A fuzzy Bayesian network (FBN) combines a Bayesian network and fuzzy set theory and converts BN node variables into fuzzy node variables. Suppose the node set of the Bayesian network is represented as:

$$
X=\left\{x_{1}, x_{2}, \ldots, x_{n}\right\}
$$

Suppose $x_{i} \in X$ can be blurred into a fuzzy random variable $y_{i}$ and all possible states of $x_{i}$ are inherited by $y_{i}$; then, the fuzzy set of $x_{i}$ is:

$$
y_{i}=\left\{y_{i 1}, y_{i 2}, \ldots, y_{i k}\right\}
$$

...where $k$ is the number of fuzzy states of $y_{i}$ and

$$
y_{i j}=\left\{x_{i}, y_{i j}(x) \mid x_{i} \in X\right\}
$$

Suppose $Y=\left\{y_{1}, y_{2}, \ldots, y_{n}\right\}$ and a directed line segment is used to represent the causal dependence of variables as follows:

$$
L=\left\{\left(y_{i}, y_{j}\right) \mid i \neq j, i=1,2, \cdots, n, j=1,2, \cdots, n\right\} \subset Y \times Y
$$

Conditional probability is used to represent the probability of causal dependence as follows:

$$
P=\left\{P\left(y_{i} \mid E\left(y_{i}\right)\right) \mid i=1,2, \ldots, n\right\}
$$

...where $E\left(y_{i}\right)$ represents the parent node set of the fuzzy variable $y_{i}$.

In conclusion, the fuzzy Bayesian network can be expressed as:

$$
F B N=\{Y, L, P\}
$$

\section{Establishment of the Risk Evaluation Model for Gas Tunnel}

In this paper, a combined method of PCA, the FISM model, and an FBN is used to construct a gas tunnel safety risk assessment model based on a fuzzy Bayesian network from two aspects of risk probability assessment and risk hazard degree. First, PCA is used to analyze the influencing factors of gas safety risk in tunnels, extract the key factors, and construct the safety risk index system. Then, a FISM is constructed and transformed into a FBN [39], and the fuzzy Bayesian network is calculated. Next, the risk index weight and hazard value are combined to obtain the risk hazard degree value and. Finally, the gas tunnel safety risk value and risk level. A flow chart of gas tunnel risk assessment is established in Fig.3.

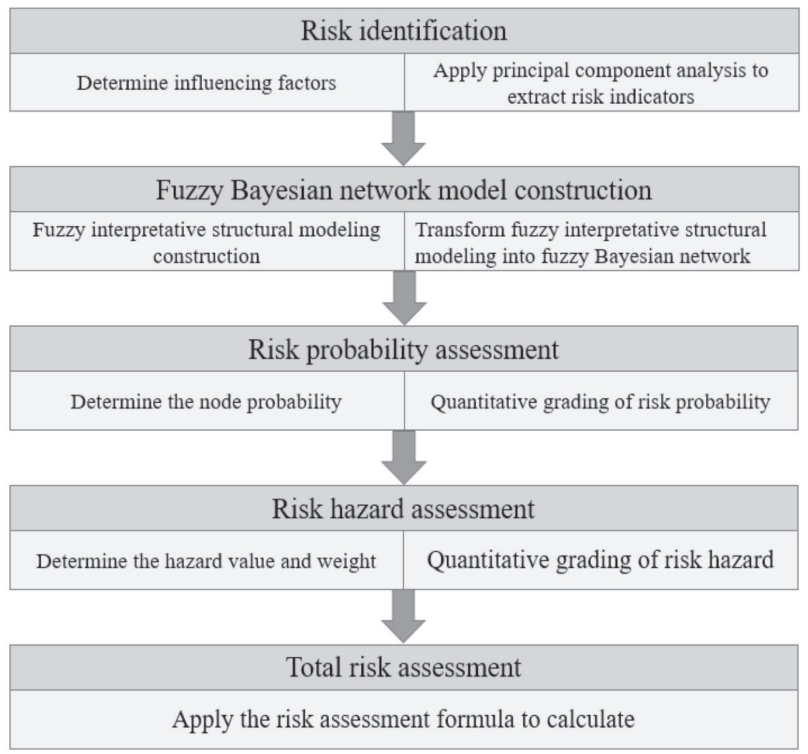

Fig. 3. A flow chart of gas tunnel risk assessment. 
Table 2. Important factors of gas tunnel safety risk.

\begin{tabular}{|c|c|c|c|}
\hline Classification & Factors & Classification & Factors \\
\hline \multirow{5}{*}{ A } & A1. Gas emission quantity & \multirow{9}{*}{ B } & $\begin{array}{c}\text { B12. Rationality of starting and stopping } \\
\text { work }\end{array}$ \\
\hline & A2. Coal seam gas content & & B13. Timeliness of surrounding rock closure \\
\hline & A3. Hydrogeological condition & & B14. Availability of workers on duty \\
\hline & A4. Geological structure & & $\begin{array}{l}\text { B15. Standardization of calibration of manual } \\
\text { gas detector }\end{array}$ \\
\hline & A5. Coal seam thickness & & $\begin{array}{l}\text { B16. Standardization of automatic monitor } \\
\text { maintenance }\end{array}$ \\
\hline \multirow{11}{*}{ B } & B1. Quantity and quality of workers & & B17. Normality of fan operation \\
\hline & B2. Quantity and quality of equipment & & B18. Quality of supporting \\
\hline & B3. Accuracy of manual gas detector & & B19. Regulation of fire management \\
\hline & $\begin{array}{c}\text { B4. Standardization of manual gas detection } \\
\text { time }\end{array}$ & & B20. Standardization of blasting excavation \\
\hline & B5. Reliability of automatic gas monitor & \multirow{4}{*}{$\mathrm{C}$} & $\mathrm{C} 1$. Experience in gas tunnel construction \\
\hline & B6. Rationality of sensor layout & & C2. Excessive pursuit of economic interests \\
\hline & B7. Standardization of manual gas detection site & & C3. Accuracy of geological surveys \\
\hline & $\begin{array}{l}\text { B8. Reasonable treatment of gas near mechani- } \\
\text { cal and electrical equipment }\end{array}$ & & C4. Reliability of emergency equipment \\
\hline & $\begin{array}{c}\text { B9. Rationality of local gas accumulation } \\
\text { treatment }\end{array}$ & \multirow{3}{*}{$\mathrm{D}$} & $\begin{array}{l}\text { D1. Perfection of gas monitoring and } \\
\text { management system }\end{array}$ \\
\hline & B10. Standardization of air supply & & D2.Rationality of safety management system \\
\hline & B11. Rationality of ventilation length & & D3. Rationality of contingency plan \\
\hline
\end{tabular}

\section{Risk Identification of Like Tunnel}

Based on the analysis and summary of gas accidents in tunnels in China in the last 20 years, this study found that the occurrence of some gas accidents is caused by multiple factors. This paper reviews relevant literature and summarizes previous research methods [40]. Under the premise of fully understanding the engineering conditions of tunnel construction, geological data, design materials, and construction organization plans are used for statistical analysis. Thus, 32 important factors could be obtained from 4 dimensions: A. Natural factors; B. Gas management factors; C. Relevant units; D. Safety regime. (Table 2).

To ensure the integrity of the original information to some extent, this paper adopts a method of the accumulation variance contribution rate exceeding a certain standard to extract the principal components.

Calculate the covariance matrix:

$$
R=\frac{1}{s-1} Y^{T} Y=\frac{1}{s-1} \cdot\left[\begin{array}{cccc}
y_{11} & y_{12} & \ldots & y_{s 1} \\
y_{21} & y_{22} & \ldots & y_{s 2} \\
\vdots & \vdots & \ddots & \vdots \\
y_{1 m} & y_{2 m} & \ldots & y_{s m}
\end{array}\right]\left[\begin{array}{cccc}
y_{11} & y_{12} & \ldots & y_{1 m} \\
y_{21} & y_{22} & \ldots & y_{2 m} \\
\vdots & \vdots & \ddots & \vdots \\
y_{s 1} & y_{s 2} & \ldots & y_{s m}
\end{array}\right]
$$

Obtain the eigenvalue $\lambda_{i}, i=1,2, \ldots, m$; the corresponding eigenvector is: $w_{1}, w_{2}, \ldots, w_{m} ; \lambda_{i}$ is the variance of a principal component, and the contribution rate of the $i$ th principal component is:

$$
e_{i}=\frac{\lambda_{i}}{\sum_{i=1}^{m} \lambda_{k}}
$$

The cumulative contribution rate of principal components represents the proportion of the information contained in the first $l$ principal components to the total information of the original index and reflects the comprehensive ability of the information contained in the new variable, which is quantified by the ratio of the variance of the first $l$ principal components to the total variance:

$$
\sum_{i=1}^{m} e_{i}=\frac{\sum_{k=1}^{l} \lambda_{k}}{\sum_{k=1}^{m} \lambda_{k}}
$$

SPSS software [41] was used to conduct principal component analysis of 32 selected data on factors 
Table 3. The measured gas concentration of "one blasting and three detections" in the arch of the tunnel face.

\begin{tabular}{|c|c|c|c|}
\hline & $\begin{array}{c}\text { Before installing } \\
\text { explosives } \\
(\%)\end{array}$ & $\begin{array}{c}\text { Before } \\
\text { the blasting } \\
(\%)\end{array}$ & $\begin{array}{c}\text { After } \\
\text { the blasting } \\
(\%)\end{array}$ \\
\hline 1 & 0.03 & 0.03 & 0.16 \\
\hline 2 & 0.03 & 0.03 & 0.22 \\
\hline 3 & 0.03 & 0.04 & 0.20 \\
\hline 4 & 0.03 & 0.03 & 0.21 \\
\hline 5 & 0.03 & 0.03 & 0.24 \\
\hline 6 & 0.03 & 0.04 & 0.19 \\
\hline 7 & 0.03 & 0.04 & 0.18 \\
\hline 8 & 0.04 & 0.05 & 0.29 \\
\hline 9 & 0.02 & 0.03 & 0.23 \\
\hline 10 & 0.03 & 0.03 & 0.23 \\
\hline
\end{tabular}

affecting the safety risk of gas tunnels using descriptive statistical analysis methods in management statistics. The indicator data of the excavation section of the Like tunnel is obtained by consulting the data and onsite investigations. Experts in the field of gas tunnel construction, site management personnel of gas tunnels and first-line technicians are invited to determine the indicator data based on their own knowledge and experience, on-site construction management and measured gas concentration values (Table 3-4). The indicator data are based on the quality of the indicator. The better the state is, the higher the value, while the worse the state is, the smaller the value, and the value range is $0-10$.

The gas concentration in key parts of the tunnel can directly reflect the natural conditions, treatment conditions and hazard degree of the working surface. During the construction of the Like tunnel, the automatic gas monitor monitors the key parts for $24 \mathrm{~h}$,

Table 4. Daily measurement of gas concentration in key parts.

\begin{tabular}{|c|c|c|c|c|c|c|c|c|}
\hline & 1 & 2 & 3 & 4 & 5 & 6 & 7 & 8 \\
\hline The vault at which the waterproofing trolley stands (\%) & 0.16 & 0.10 & 0.15 & 0.10 & 0.15 & 0.25 & 0.17 & 0.12 \\
\hline The cavity at the arch of the initial branch (\%) & 0.22 & 0.24 & 0.19 & 0.09 & 0.11 & 0.28 & 0.38 & 0.23 \\
\hline
\end{tabular}

a)

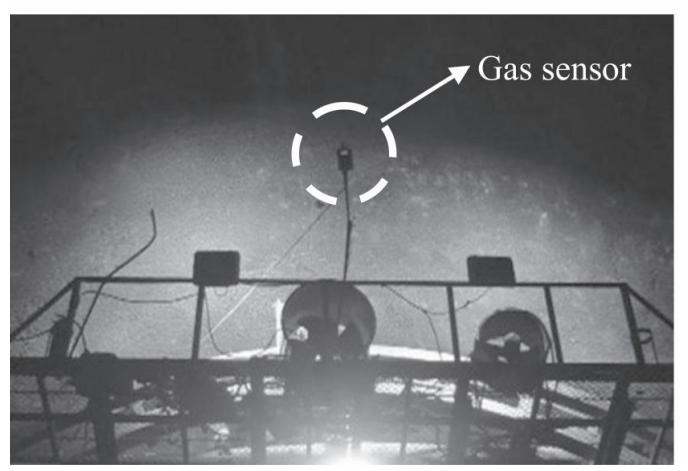

b)

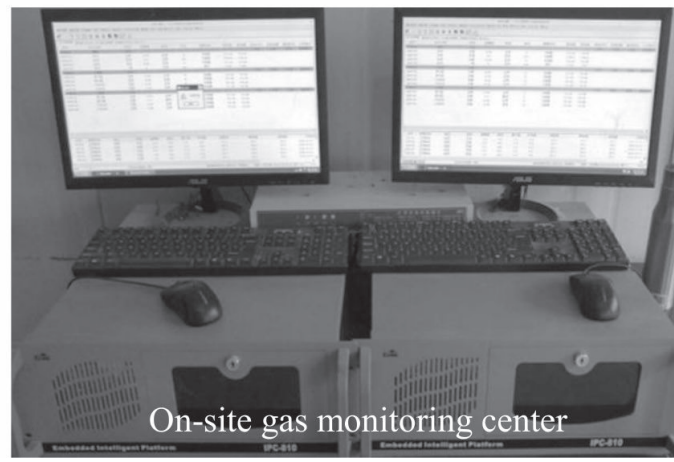

Fig. 4. Automatic gas monitoring at the construction site.

a)

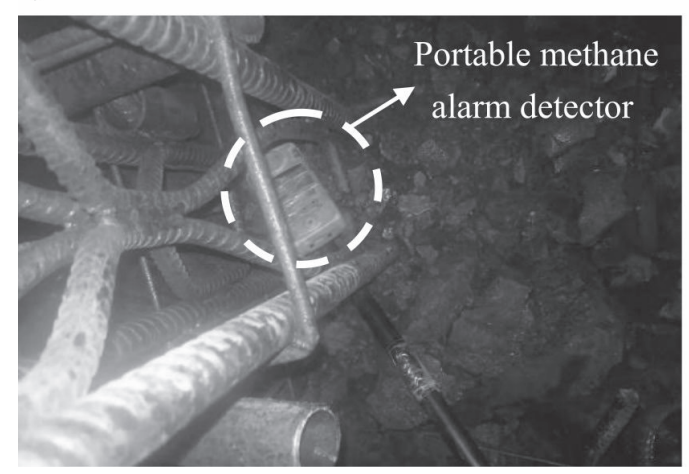

b)

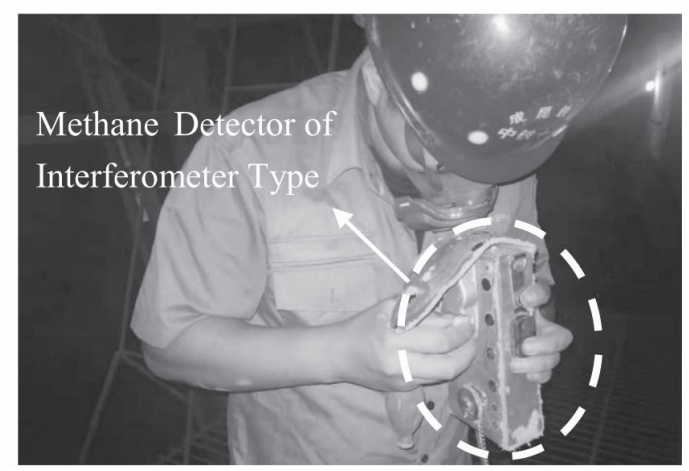

Fig. 5. Manual gas detection at the construction site. 
Table 5. KMO and Bartlett's Test.

\begin{tabular}{|c|c|c|}
\hline \multicolumn{2}{|c|}{$\begin{array}{c}\text { Kaiser- Meyer-Olkin Measure of Sampling } \\
\text { Adequacy }\end{array}$} & 0.645 \\
\hline \multirow{3}{*}{$\begin{array}{c}\text { Bartlett's Test of } \\
\text { Sphericity }\end{array}$} & $\begin{array}{c}\text { Approx. } \\
\text { Chi-Square }\end{array}$ & 2427.901 \\
\cline { 2 - 3 } & $\mathrm{df}$ & 496 \\
\cline { 2 - 3 } & Sig. & 0.000 \\
\hline
\end{tabular}

and requires manual detection of the key parts every 2 hours. The manual detection instrument is a methane detector of interferometer type and a portable methane alarm detector. The key parts are the face vault, the left vault at which the lower step, the right vault at which the lower step, the $20 \mathrm{~m}$ near the face, the vault at which the waterproofing trolley stands, the vault at which the second lining trolley stands, the reserved cave, the vault of the return air. Focus on the gas concentration in the "one blasting and three detections". Within $20 \mathrm{~m}$ of the blasting site, the gas concentration in the air flow must be less than $0.5 \%$. Within $20 \mathrm{~m}$ in the fire working place such as welding and cutting, the gas concentration must be less than $0.3 \%$. The gas monitoring and detection at the construction site are shown in Figs 4-5. Through the analysis of monitoring and detection data, the gas concentration of the "one blasting and three detections", the vault at which the waterproofing trolley stands and the cavity at the arch of the initial branch is high, the above three are the key points of concern, and as an important reference for risk identification.

According to the Kaiser standard, if $\mathrm{KMO}>0.6$, the index data are suitable for factor analysis, and the probability of the Bartlett test is 0.000 , less than 0.05 (Table 5). In conclusion, the 32 important factors are suitable for factor analysis.

According to the rotated component matrix (Table 6), This paper summarizes the principal component analysis of the important factors affecting the safety risk of gas tunnel construction and the relationships between the principal components and the important factors, 12 principal components were extracted (Table 7).

\section{Establishment of a Fuzzy Bayesian Network Model}

(1) Establishment of the fuzzy correlation matrix.

Expert elicitation is an effective way of dealing with uncertainty and a lack of sufficient data for assessing risks [42]. A questionnaire survey is adopted in this paper, and the survey objects are industry experts, site management, and construction personnel. This paper invited 3 experts in the field of gas tunnel construction, 2 field construction managers and 2 field gas detection technicians to evaluate the relationships between the key factors. They rated each of the 12 key factors on a scale of $0-1$ based on their knowledge and practical experience. A fuzzy correlation matrix of the key influencing factors for the safety risk assessment of gas tunnel construction is obtained using the average statistical factor fuzzy correlation relation. Determine the fuzzy correlation matrix $X=\left[x_{i j}\right]_{m \times m}$, $x_{i j} \in[0,1]$.

(2) Establishment of the adjacency matrix.

To cluster the indexes with similar characteristics, establish the correlation intensity matrix $Y=\left[y_{i j}\right]_{m \times m}$, $y_{i j} \in[0,1][43]$.

$$
y_{i j}=\frac{x_{i j}}{x_{i \cdot}+x_{\cdot j}+x_{i j}}
$$

The closer the value is to 1 , the stronger the correlation is. For the opposite, the correlation is weaker. Find the intercept matrix $Z=\left[z_{i j}\right]_{m \times m}$ at the level $\lambda$ based on the adjacency matrix $Y$. $\lambda$ reflects the thickness of risk management. The smaller the value of $\lambda$ is, the more refined the risk management. For the opposite, risk management is more extensive. In this paper, $\lambda=0.08$ is used to obtain the adjacency matrix.

$$
z_{i j}=\left\{\begin{array}{l}
1, y_{i j} \geq \lambda \\
0, y_{i j}<\lambda
\end{array}\right.
$$

...where matrix $Z=\left[z_{i j}\right]_{m \times m}$ is considered the adjacency matrix at the level.

(4) The solution of the reachable matrix.

Solve the adjacency matrix $Z=\left[z_{i j}\right]_{m \times m}$ at the level $\lambda$ by a Boolean operation to obtain the reachable matrix $A=\left[a_{i j}\right]_{m \times m}($ Table 8$)$.

...where

$$
a_{i j}=\left\{\begin{array}{l}
1, \mathrm{Qm} \text { is related to Qn } \\
0, \mathrm{Qm} \text { is not related to Qn }
\end{array}\right.
$$

...where Qm and Qn are principal components, $m=1,2, \ldots, 12, n=1,2, \ldots, 12$.

(5) Hierarchical division of key factors.

If the elements are the same in the set and the intersection, the element belongs to level 1 and is placed at the top of the FISM level, and the above steps are repeated until the level of all elements is determined. The stratification of the key influencing factors of the safety risk assessment of gas tunnel construction in this paper is divided into 5 layers, and the division process is as follows (Table 9).

According to the hierarchical division results of the key influencing factors, the fuzzy interpretive structural model of the Like tunnel safety risk assessment is established. The set of level 1 influence indexes is [Q1,Q4,Q10], the set of level 2 influence indexes is [Q2, Q6], the set of level 3 influence indexes is [Q3,Q5,Q8,Q9], the set of level 4 influence indexes is [Q7,Q12], and the set of level 5 influence indexes is [Q11]. 
Table 6. Rotated Component Matrix.

\begin{tabular}{|c|c|c|c|c|c|c|c|c|c|c|c|c|}
\hline \multirow{2}{*}{ Important factors } & \multicolumn{12}{|c|}{ Component } \\
\hline & 1 & 2 & 3 & 4 & 5 & 6 & 7 & 8 & 9 & 10 & 11 & 12 \\
\hline A1. Gas emission quantity & 0.045 & -0.065 & -0.046 & 0.091 & 0.099 & 0.913 & 0.054 & -0.066 & -0.173 & 0.028 & 0.053 & -0.035 \\
\hline A2. Coal seam gas content & 0.057 & -0.051 & -0.087 & 0.090 & -0.010 & 0.933 & 0.022 & 0.013 & -0.066 & 0.017 & 0.002 & 0.011 \\
\hline A3. Hydrogeological condition & 0.003 & -0.111 & 0.183 & -0.125 & 0.008 & -0.149 & 0.001 & 0.022 & 0.936 & 0.082 & 0.049 & 0.083 \\
\hline A4. Geological structure & -0.008 & -0.158 & 0.230 & -0.088 & 0.024 & -0.106 & -0.081 & -0.008 & 0.932 & 0.095 & 0.029 & 0.056 \\
\hline A5. Coal seam thickness & 0.126 & -0.015 & 0.011 & -0.058 & 0.006 & 0.868 & -0.053 & 0.047 & -0.004 & -0.081 & 0.033 & 0.040 \\
\hline $\begin{array}{l}\text { B1. Quantity and quality of } \\
\text { workers }\end{array}$ & -0.012 & 0.239 & 0.834 & -0.043 & -0.091 & 0.009 & 0.183 & 0.105 & 0.240 & -0.099 & -0.050 & -0.011 \\
\hline $\begin{array}{c}\text { B2. Quantity and quality of } \\
\text { equipment }\end{array}$ & 0.113 & 0.893 & 0.205 & 0.117 & 0.124 & -0.066 & 0.117 & 0.077 & -0.065 & -0.136 & 0.040 & 0.060 \\
\hline $\begin{array}{l}\text { B3. Accuracy of manual gas } \\
\text { detection instrument }\end{array}$ & -0.092 & 0.911 & 0.207 & 0.009 & 0.047 & 0.040 & 0.129 & 0.083 & -0.083 & -0.032 & -0.111 & -0.041 \\
\hline $\begin{array}{l}\text { B4. Standardization of manual } \\
\text { gas detection time }\end{array}$ & -0.096 & 0.230 & 0.868 & -0.027 & -0.047 & -0.071 & 0.207 & 0.164 & 0.136 & -0.076 & -0.042 & -0.047 \\
\hline $\begin{array}{l}\text { B5. Reliability of automatic gas } \\
\text { monitor }\end{array}$ & 0.101 & 0.906 & 0.138 & 0.029 & -0.054 & -0.122 & 0.202 & 0.097 & -0.044 & -0.097 & 0.007 & 0.052 \\
\hline B6. Rationality of sensor layout & -0.058 & 0.932 & 0.183 & 0.000 & 0.001 & -0.017 & 0.059 & 0.090 & -0.095 & -0.025 & -0.094 & -0.011 \\
\hline $\begin{array}{l}\text { B7. Standardization of artificial } \\
\text { gas detection site }\end{array}$ & 0.022 & 0.223 & 0.806 & -0.219 & -0.068 & 0.016 & 0.283 & 0.038 & 0.094 & 0.108 & 0.021 & 0.031 \\
\hline $\begin{array}{c}\text { B8.Reasonable treatment of gas } \\
\text { near mechanical and electrical } \\
\text { equipment }\end{array}$ & 0.964 & 0.040 & -0.003 & 0.052 & -0.013 & 0.029 & 0.117 & -0.077 & -0.030 & -0.035 & -0.049 & 0.024 \\
\hline $\begin{array}{l}\text { B9. Rationality of local gas } \\
\text { accumulation treatment }\end{array}$ & 0.961 & 0.097 & -0.034 & 0.062 & 0.046 & 0.059 & 0.062 & -0.027 & 0.007 & -0.056 & -0.051 & -0.010 \\
\hline $\begin{array}{l}\text { B10. Standardization of air } \\
\text { supply }\end{array}$ & 0.078 & 0.031 & -0.075 & 0.971 & -0.010 & -0.004 & -0.034 & 0.032 & -0.062 & 0.008 & 0.017 & -0.052 \\
\hline $\begin{array}{l}\text { B11. Rationality of ventilation } \\
\text { length }\end{array}$ & 0.047 & 0.034 & -0.081 & 0.968 & -0.058 & 0.050 & -0.061 & 0.013 & -0.066 & 0.042 & 0.044 & -0.038 \\
\hline $\begin{array}{l}\text { B12. Rationality of starting and } \\
\text { stopping work }\end{array}$ & 0.953 & -0.056 & -0.014 & -0.077 & -0.023 & 0.095 & 0.118 & 0.006 & 0.002 & -0.014 & 0.035 & -0.027 \\
\hline $\begin{array}{l}\text { B13. Timeliness of surrounding } \\
\text { rock closure }\end{array}$ & -0.041 & 0.050 & -0.083 & -0.063 & 0.969 & 0.037 & -0.007 & -0.013 & 0.067 & 0.051 & -0.029 & -0.014 \\
\hline $\begin{array}{l}\text { B14. Availability of workers on } \\
\text { duty }\end{array}$ & -0.050 & 0.131 & 0.888 & 0.005 & 0.115 & -0.115 & 0.256 & 0.067 & 0.067 & -0.032 & -0.016 & 0.085 \\
\hline $\begin{array}{l}\text { B15. Standardization of } \\
\text { calibration of artificial gas } \\
\text { detector }\end{array}$ & -0.050 & 0.155 & 0.158 & 0.032 & -0.086 & 0.016 & 0.121 & 0.944 & 0.009 & 0.038 & -0.065 & 0.076 \\
\hline $\begin{array}{l}\text { B16.Standardization of } \\
\text { automatic monitor maintenance }\end{array}$ & -0.071 & 0.139 & 0.133 & 0.097 & -0.016 & -0.013 & 0.159 & 0.944 & 0.006 & 0.003 & -0.012 & 0.089 \\
\hline B17. Normality of fan operation & -0.009 & 0.058 & -0.043 & 0.938 & -0.076 & 0.073 & -0.093 & 0.079 & -0.072 & 0.082 & 0.040 & -0.077 \\
\hline B18. Quality of supporting & -0.010 & 0.031 & 0.003 & -0.050 & 0.982 & 0.020 & 0.010 & -0.053 & 0.033 & -0.012 & 0.005 & 0.014 \\
\hline $\begin{array}{l}\text { B19. Regulation of fire } \\
\text { management }\end{array}$ & 0.972 & -0.035 & -0.038 & 0.086 & -0.026 & 0.072 & 0.049 & -0.026 & 0.010 & -0.049 & -0.014 & -0.057 \\
\hline $\begin{array}{l}\text { B20. Standardization of blasting } \\
\text { excavation }\end{array}$ & 0.034 & 0.007 & 0.021 & -0.025 & 0.952 & 0.032 & -0.059 & -0.031 & -0.073 & -0.010 & 0.080 & -0.012 \\
\hline $\begin{array}{l}\text { C1. Experience in gas tunnel } \\
\text { construction }\end{array}$ & 0.191 & 0.256 & 0.383 & -0.084 & -0.016 & 0.020 & 0.827 & 0.118 & -0.063 & 0.009 & -0.050 & -0.053 \\
\hline $\begin{array}{l}\text { C2. Excessive pursuit of } \\
\text { economic interests }\end{array}$ & -0.062 & 0.042 & 0.037 & -0.163 & -0.013 & 0.025 & -0.080 & 0.158 & 0.127 & -0.003 & -0.081 & 0.951 \\
\hline
\end{tabular}


Table 6. Continued.

\begin{tabular}{|c|c|c|c|c|c|c|c|c|c|c|c|c|}
\hline $\begin{array}{c}\text { C3. Accuracy of geological } \\
\text { surveys }\end{array}$ & -0.075 & -0.128 & -0.064 & 0.095 & 0.057 & 0.087 & -0.135 & -0.071 & 0.070 & 0.069 & $\mathbf{0 . 9 5 2}$ & -0.081 \\
\hline $\begin{array}{c}\text { C4. Reliability of emergency } \\
\text { equipment }\end{array}$ & -0.048 & -0.042 & -0.033 & 0.132 & -0.041 & -0.007 & 0.169 & -0.022 & 0.127 & $\mathbf{0 . 8 8 0}$ & 0.113 & -0.078 \\
\hline $\begin{array}{c}\text { D1. Perfection of gas monitoring } \\
\text { and management system }\end{array}$ & 0.163 & 0.118 & 0.379 & -0.086 & -0.048 & 0.008 & $\mathbf{0 . 8 3 0}$ & 0.120 & 0.024 & 0.056 & -0.077 & 0.016 \\
\hline $\begin{array}{c}\text { D2. Rationality of safety } \\
\text { management system }\end{array}$ & 0.132 & 0.243 & 0.341 & -0.097 & -0.013 & 0.002 & $\mathbf{0 . 8 3 1}$ & 0.161 & -0.078 & 0.055 & -0.079 & -0.092 \\
\hline $\begin{array}{c}\text { D3. Rationality of contingency } \\
\text { plan }\end{array}$ & -0.090 & -0.185 & -0.038 & 0.000 & 0.068 & -0.035 & -0.077 & 0.059 & 0.034 & $\mathbf{0 . 8 9 9}$ & -0.039 & 0.072 \\
\hline
\end{tabular}

Table 7. The relationship between principal components and important factors.

\begin{tabular}{|c|c|}
\hline Principal components & Important factors \\
\hline \multirow{4}{*}{ Q1. Treatment method of gas emission } & B9. Rationality of local gas accumulation treatment \\
\hline & B8. Reasonable treatment of gas near mechanical and electrical equipment \\
\hline & B12.Rationality of starting and stopping work \\
\hline & B19. Regulation of fire management \\
\hline \multirow{4}{*}{ Q2. Gas detection and monitoring instrument status } & B2.Quantity and quality of equipment \\
\hline & B3. Accuracy of manual gas detection instrument \\
\hline & B5.Reliability of automatic gas monitor \\
\hline & B6. Rationality of sensor layout \\
\hline \multirow{4}{*}{ Q3. Working status of gas detector } & B1. Quantity and quality of workers \\
\hline & B4.Standardization of manual gas detection time \\
\hline & B7.Standardization of artificial gas detection site \\
\hline & B14. Availability of workers on duty \\
\hline \multirow{3}{*}{ Q4. Standardization of ventilation } & B10. Standardization of air supply \\
\hline & B11. Rationality of ventilation length \\
\hline & B17. Normality of fan operation \\
\hline \multirow{3}{*}{ Q5. Status of tunnel construction } & B20. Standardization of blasting excavation \\
\hline & B13. Timeliness of surrounding rock closure \\
\hline & B18. Quality of supporting \\
\hline \multirow{3}{*}{ Q6. Gas factor } & A5. Coal seam thickness \\
\hline & A2. Coal seam gas content \\
\hline & A1. Gas emission quantity \\
\hline \multirow{3}{*}{ Q7. Management system of gas tunnel construction } & C1. Experience in gas tunnel construction \\
\hline & D2. Rationality of safety management system \\
\hline & D1. Perfection of gas monitoring and management system \\
\hline \multirow{2}{*}{$\begin{array}{l}\text { Q8. Maintenance of gas detection and monitoring } \\
\text { equipment }\end{array}$} & B16. Standardization of automatic monitor maintenance \\
\hline & B15. Standardization of calibration of artificial gas detector \\
\hline \multirow{2}{*}{ Q9. Geological factor } & A4. Geological structure \\
\hline & A3.Hydrogeological condition \\
\hline \multirow{2}{*}{ Q10. Emergency plan } & D3. Rationality of contingency plan \\
\hline & C4. Reliability of emergency equipment \\
\hline Q11. Preliminary survey work & C3. Accuracy of geological surveys \\
\hline Q12. The situation of the relevant units & C2. Excessive pursuit of economic interests \\
\hline
\end{tabular}


Table 8. Reachable matrix of key factors.

\begin{tabular}{|c|c|c|c|c|c|c|c|c|c|c|c|c|}
\hline Key factors & Q1 & Q2 & Q3 & Q4 & Q5 & Q6 & Q7 & Q8 & Q9 & Q10 & Q11 & Q12 \\
\hline Q1 & 1 & 0 & 0 & 0 & 0 & 0 & 0 & 0 & 0 & 0 & 0 & 0 \\
\hline Q2 & 1 & 1 & 0 & 0 & 0 & 0 & 0 & 0 & 0 & 0 & 0 & 0 \\
\hline Q3 & 1 & 1 & 1 & 0 & 0 & 0 & 0 & 0 & 0 & 0 & 0 & 0 \\
\hline Q4 & 0 & 0 & 0 & 1 & 0 & 0 & 0 & 0 & 0 & 0 & 0 & 0 \\
\hline Q5 & 1 & 0 & 0 & 1 & 1 & 1 & 0 & 0 & 0 & 1 & 0 & 0 \\
\hline Q6 & 1 & 0 & 0 & 1 & 0 & 1 & 0 & 0 & 0 & 1 & 0 & 0 \\
\hline Q7 & 1 & 1 & 1 & 1 & 1 & 1 & 1 & 1 & 0 & 1 & 0 & 0 \\
\hline Q8 & 1 & 1 & 0 & 0 & 0 & 0 & 0 & 1 & 0 & 0 & 0 & 0 \\
\hline Q9 & 1 & 0 & 0 & 1 & 0 & 1 & 0 & 0 & 1 & 1 & 0 & 0 \\
\hline Q10 & 0 & 0 & 0 & 0 & 0 & 0 & 0 & 0 & 0 & 1 & 0 & 0 \\
\hline Q11 & 1 & 1 & 1 & 1 & 1 & 1 & 1 & 1 & 0 & 1 & 1 & 0 \\
\hline Q12 & 1 & 1 & 1 & 1 & 1 & 1 & 0 & 1 & 0 & 1 & 0 & 1 \\
\hline
\end{tabular}

Table 9. Key factors hierarchy.

\begin{tabular}{|c|c|c|c|c|}
\hline Factors & Reachable set & Antecedent set & Intersection & Level \\
\hline Q1 & Q1 & Q1, Q2, Q3, Q5, Q6, Q7, Q8, Q9, Q11, Q12 & Q1 & 1 \\
\hline Q2 & Q1, Q2 & Q2, Q3, Q7, Q8, Q11, Q12 & Q2 & \\
\hline Q3 & Q1, Q2, Q3 & Q3, Q7, Q11, Q12 & Q3 & \\
\hline Q4 & Q4 & Q4, Q5, Q6, Q7, Q9, Q11, Q12 & Q4 & 1 \\
\hline Q5 & Q1, Q4, Q5, Q6, Q10 & Q5, Q7, Q11, Q12 & Q5 & \\
\hline Q6 & Q1, Q4, Q6, Q10 & Q5, Q6, Q7, Q9, Q11, Q12 & Q6 & \\
\hline Q7 & Q1, Q2, Q3, Q4, Q5, Q6, Q7, Q8, Q10 & Q7, Q11 & Q7 & \\
\hline Q8 & Q1, Q2, Q8 & Q7, Q8, Q11, Q12 & Q8 & \\
\hline Q9 & Q1, Q4, Q6, Q9, Q10 & Q9 & Q9 & \\
\hline Q10 & Q10 & Q5, Q6, Q7, Q9, Q10, Q11, Q12 & Q10 & 1 \\
\hline Q11 & Q1, Q2, Q3, Q4, Q5, Q6, Q7, Q8, Q10, Q11 & Q11 & Q11 & \\
\hline Q12 & Q1, Q2, Q3, Q4, Q5, Q6, Q8, Q10, Q12 & Q12 & Q12 & \\
\hline Q2 & Q2 & Q2, Q3, Q7, Q8, Q11, Q12 & Q2 & 2 \\
\hline Q3 & Q2, Q3 & Q3, Q7, Q11, Q12 & Q3 & \\
\hline Q5 & Q5, Q6 & Q5, Q7, Q11, Q12 & Q5 & \\
\hline Q6 & Q6 & Q5, Q6, Q7, Q9, Q11, Q12 & Q6 & 2 \\
\hline Q7 & Q2, Q3, Q5, Q6, Q7, Q8 & Q7, Q11 & Q7 & \\
\hline Q8 & Q2, Q8 & Q7, Q8, Q11, Q12 & Q8 & \\
\hline Q9 & Q6, Q9 & Q9 & Q9 & \\
\hline Q11 & Q2, Q3, Q5, Q6, Q7, Q8, Q11 & Q11 & Q11 & \\
\hline Q12 & Q2, Q3, Q5, Q6, Q8, Q12 & Q12 & Q12 & \\
\hline Q3 & Q3 & Q3, Q7, Q11, Q12 & Q3 & 3 \\
\hline Q5 & Q5 & Q5, Q7, Q11, Q12 & Q5 & 3 \\
\hline Q7 & Q3, Q5, Q7, Q8 & Q7, Q11 & Q7 & \\
\hline
\end{tabular}


Table 9. Continued.

\begin{tabular}{|c|c|c|c|c|}
\hline Q8 & Q8 & Q7, Q8, Q11, Q12 & Q8 & 3 \\
\hline Q9 & Q9 & Q9 & Q9 & 3 \\
\hline Q11 & Q3, Q5, Q7, Q8, Q11 & Q11 & Q11 & \\
\hline Q12 & Q3, Q5, Q8, Q12 & Q12 & \\
\hline Q7 & Q7 & Q7, Q11 & Q7 & 4 \\
\hline Q11 & Q7, Q11 & Q11 & \\
\hline Q12 & Q12 & Q12 & Q12 & 4 \\
\hline Q11 & Q11 & Q11 & Q11 & 5 \\
\hline
\end{tabular}

(6) Convert the FISM into an FBN structural model.

Convert the corresponding influencing factors in the FISM into nodes in the FBN to determine the node states. Causal relationships in the FISM are converted to directed edges in the FBN, and finally, the safety risk probability $\mathrm{P}$ of gas tunnel construction is taken as the target layer, and the fuzzy Bayesian network model of the gas tunnel risk assessment is established (Fig. 6).

(7) Calculate the node parameters in the FBN.

Experts are invited to evaluate different states of each node, and the prior probabilities and probability distribution tables of sub-nodes are obtained by using fuzzy set theory.

Suppose that the judicial opinion of the nth expert on node $S_{i}$ in state $j$ is obtained through triangular fuzzy transformation and the triangular fuzzy probability is:

$$
P_{i j}{ }^{n}=\left(a_{i j}{ }^{n}, b_{i j}{ }^{n}, c_{i j}{ }^{n}\right)
$$

To obtain a reasonable fuzzy probability value, the evaluation results given by various experts are calculated by the arithmetic mean, and the probability of the fuzzy mean is:

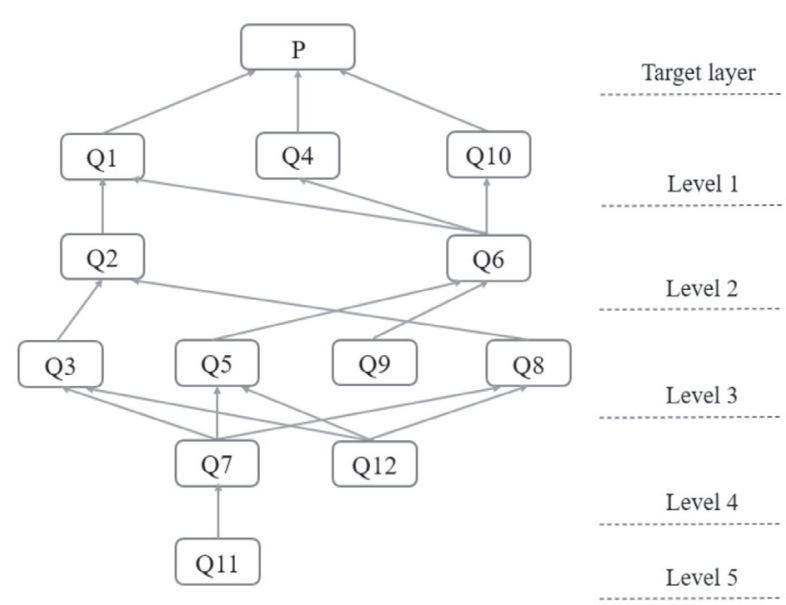

Fig. 6. FBN structure diagram of gas tunnel construction safety risk.

$$
P_{i j}^{\prime \prime}=\frac{P_{i j}^{1}+\ldots+P_{i j}^{k}+\ldots+P_{i j}^{n}}{n}=\left(a_{i j}^{\prime \prime}, b_{i j}^{\prime \prime}, c_{i j}\right)
$$

The probability value of calculating the fuzzy set is:

$$
P_{i j}^{\prime}=\frac{a_{i j}^{\prime \prime}+2 b_{i j}^{\prime \prime}+c_{i j}^{\prime \prime}}{4}
$$

Normalize the probability values of nodes in different states, and obtain the prior probability and conditional probability distributions as follows:

$$
P_{i j}=\frac{P_{i j}^{\prime}}{\sum_{j=0}^{k} P_{i j}^{\prime}}
$$

\section{Probability Assessment of Tunnel Construction Safety Risk}

Gas tunnel construction involves many risks, so there will be many nodes in the fuzzy Bayesian network structure. In this paper, each node state is divided into two categories: the risk probability under an acceptable state (Yes) and the risk probability under an unacceptable state (No). The prior probability and conditional probability under each state are obtained by expert assignment. The Bayesian network model structure is constructed, and the total risk probability value $\mathrm{P}$ of gas tunnel construction is calculated. According to the data of gas tunnels that have been built or are under construction, the risk probability assessment of gas tunnel construction is compared with the actual situation of project sites to establish a quantified grading system of gas tunnel risk probability (Table 10).

This paper adopts Netica software [44] to calculate the Bayesian network model. Netica software is mainly used for Bayesian network simulation and is developed by Norsys, has a concise graphical user interface and is one of the most widely used and comprehensive Bayesian network analysis software in the world.

Prior probabilities and conditional probabilities are obtained from experts after analyzing and evaluating 
Table 10 . The grading of risk probability levels

\begin{tabular}{|c|c|c|}
\hline Probability interval & Levels description & Level \\
\hline$\geq 0.70$ & Very high & I \\
\hline $0.50-0.70$ & High & II \\
\hline $0.30-0.50$ & Medium & III \\
\hline $0.2-0.30$ & Low & IV \\
\hline$\leq 0.20$ & Very low & V \\
\hline
\end{tabular}

previous similar projects. A prior probability is the probability value of a root node. A conditional probability is the probability value of each state of a node given any possible combination of states of all the parent nodes. The three experts participating in the project risk assessment have rich experience in gas tunnel risk assessment. By natural language assessment, the fuzzy prior probability (Appendix A, Tables A1) and fuzzy conditional probability distribution tables (Appendix A, Tables A2-A5) of Bayesian network nodes in segment \#1 and segment \#2 are obtained.

Table 11. Fuzzy Bayesian network nodes probability distribution

\begin{tabular}{|c|c|c|c|c|}
\hline & \multicolumn{2}{|c|}{ \#1 } & \multicolumn{2}{|c|}{ \#2 } \\
\hline Node & $Y$ & $N$ & Y & $N$ \\
\hline Q11 & 0.703 & 0.297 & 0.746 & 0.254 \\
\hline Q12 & 0.633 & 0.367 & 0.743 & 0.257 \\
\hline Q9 & 0.726 & 0.274 & 0.772 & 0.228 \\
\hline \multirow{2}{*}{ Q7 } & 0.800 & 0.200 & 0.874 & 0.126 \\
\hline & 0.393 & 0.607 & 0.559 & 0.441 \\
\hline \multirow{4}{*}{ Q3 } & 0.804 & 0.196 & 0.804 & 0.196 \\
\hline & 0.370 & 0.630 & 0.433 & 0.567 \\
\hline & 0.464 & 0.536 & 0.567 & 0.433 \\
\hline & 0.163 & 0.837 & 0.173 & 0.827 \\
\hline \multirow{4}{*}{ Q5 } & 0.690 & 0.310 & 0.669 & 0.331 \\
\hline & 0.410 & 0.590 & 0.636 & 0.364 \\
\hline & 0.500 & 0.500 & 0.591 & 0.409 \\
\hline & 0.199 & 0.801 & 0.572 & 0.428 \\
\hline \multirow{4}{*}{ Q8 } & 0.591 & 0.409 & 0.615 & 0.385 \\
\hline & 0.210 & 0.790 & 0.367 & 0.633 \\
\hline & 0.469 & 0.531 & 0.500 & 0.500 \\
\hline & 0.107 & 0.893 & 0.210 & 0.790 \\
\hline \multirow{4}{*}{ Q2 } & 0.690 & 0.310 & 0.690 & 0.310 \\
\hline & 0.288 & 0.712 & 0.656 & 0.344 \\
\hline & 0.861 & 0.139 & 0.800 & 0.200 \\
\hline & 0.158 & 0.842 & 0.417 & 0.583 \\
\hline
\end{tabular}

Based on the membership functions of natural language variables and triangular fuzzy numbers, the prior probability and conditional probability values of nodes are calculated (Table 11).

Netica software was used to establish the safety risk for the Bayesian network structure of gas tunnel segment $\# 1$ and segment $\# 2$ and calculate the risk probability value (Figs 7-8).

According to the calculation of the fuzzy Bayesian network model, the level of safety risk probability of segment \#1 is level II under an unacceptable state, and the level of safety risk probability of segment \#2 is level III under an unacceptable state.

\section{Assessment of Degree of Hazard in Tunnel Construction}

The degree of risk of harm is interpreted as the degree of influence and the amount of loss caused by the occurrence of adverse conditions for each risk. Because the precise degree of risk damage is difficult to determine, this paper uses the expert valuation method to quantify it. The risk index weight $q_{i}$ was obtained by

\begin{tabular}{|c|c|c|c|c|}
\hline & \multicolumn{2}{|c|}{ \#1 } & \multicolumn{2}{|c|}{ \#2 } \\
\hline Node & Y & $N$ & Y & $N$ \\
\hline \multirow{4}{*}{ Q6 } & 0.636 & 0.364 & 0.674 & 0.326 \\
\hline & 0.725 & 0.275 & 0.659 & 0.341 \\
\hline & 0.642 & 0.358 & 0.654 & 0.346 \\
\hline & 0.163 & 0.837 & 0.323 & 0.677 \\
\hline \multirow{4}{*}{ Q1 } & 0.672 & 0.328 & 0.674 & 0.326 \\
\hline & 0.367 & 0.633 & 0.633 & 0.367 \\
\hline & 0.469 & 0.531 & 0.559 & 0.441 \\
\hline & 0.210 & 0.790 & 0.633 & 0.367 \\
\hline \multirow{2}{*}{ Q4 } & 0.636 & 0.364 & 0.942 & 0.058 \\
\hline & 0.326 & 0.674 & 0.731 & 0.269 \\
\hline \multirow{2}{*}{ Q10 } & 0.899 & 0.101 & 0.883 & 0.117 \\
\hline & 0.528 & 0.472 & 0.580 & 0.420 \\
\hline \multirow{8}{*}{$\mathrm{P}$} & 0.940 & 0.060 & 0.940 & 0.060 \\
\hline & 0.469 & 0.531 & 0.531 & 0.469 \\
\hline & 0.276 & 0.724 & 0.433 & 0.567 \\
\hline & 0.208 & 0.792 & 0.542 & 0.458 \\
\hline & 0.195 & 0.805 & 0.553 & 0.447 \\
\hline & 0.133 & 0.867 & 0.433 & 0.567 \\
\hline & 0.090 & 0.910 & 0.464 & 0.536 \\
\hline & 0.060 & 0.940 & 0.310 & 0.690 \\
\hline
\end{tabular}




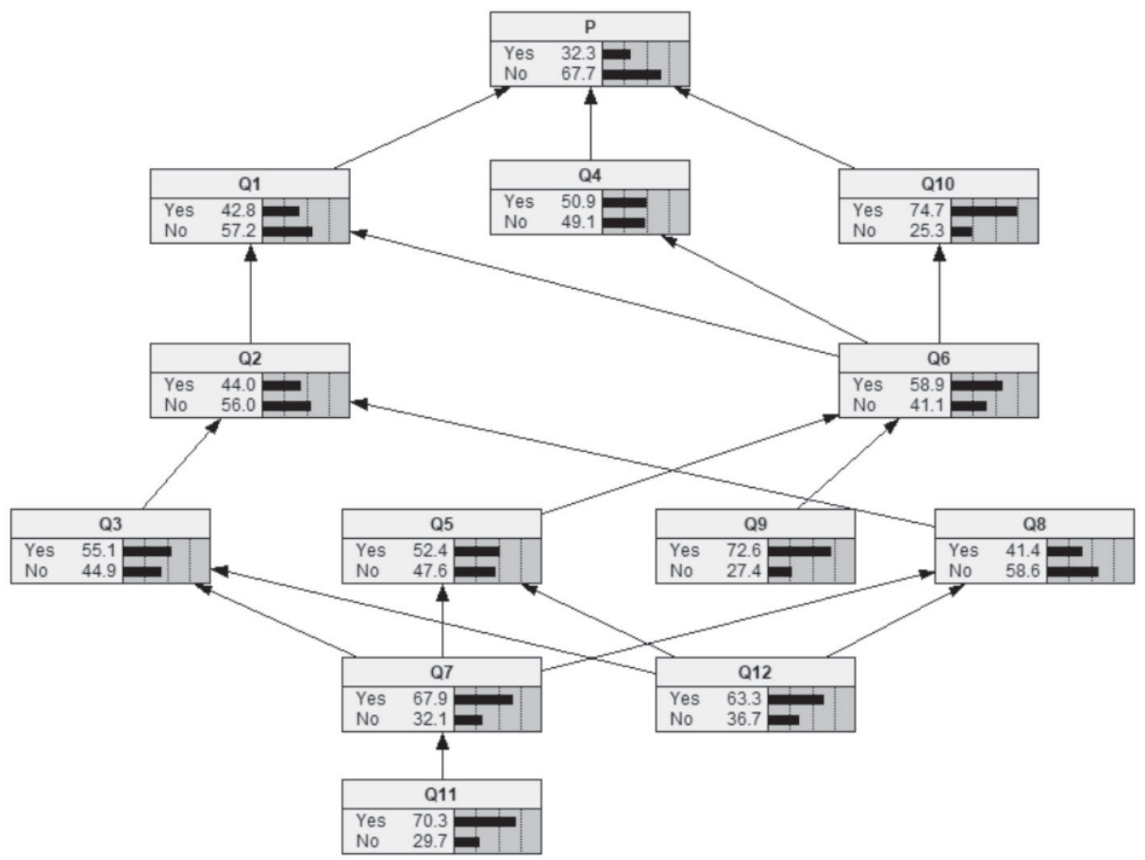

Fig. 7. Safety risk fuzzy Bayesian network model in segment \#1.

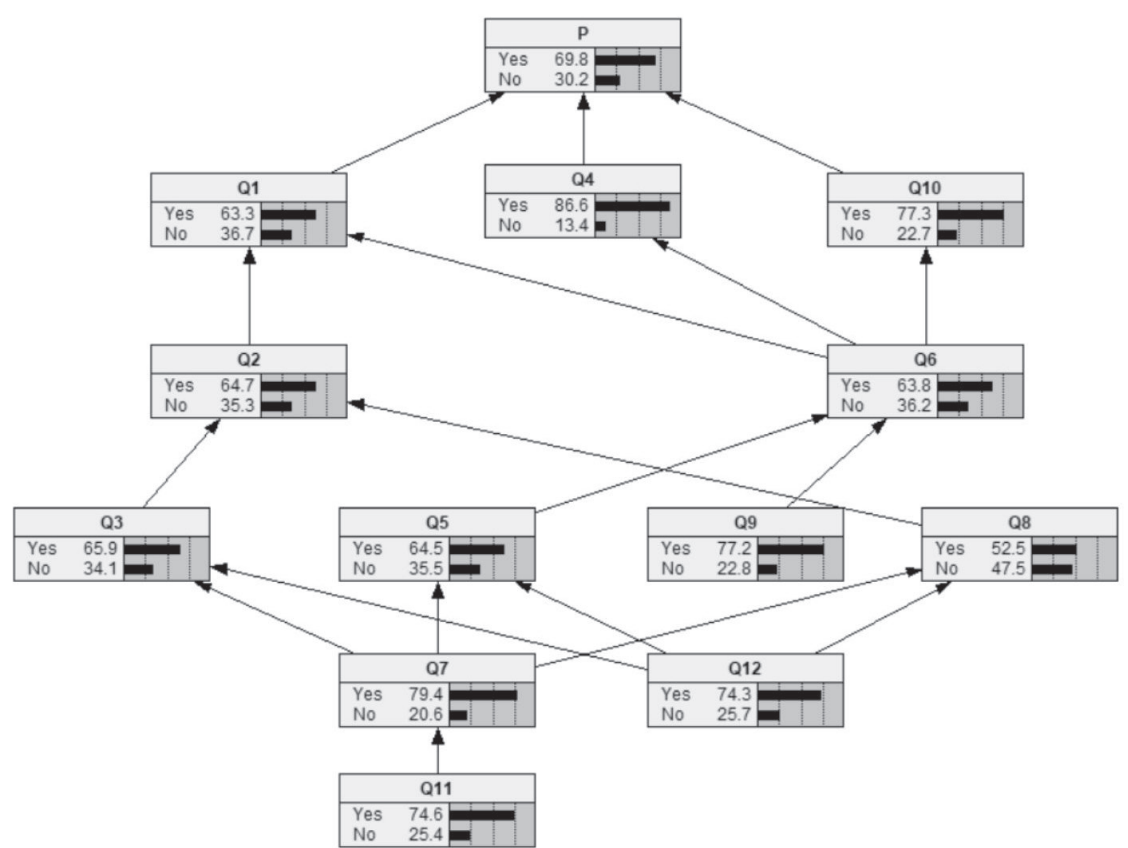

Fig. 8. Safety risk fuzzy Bayesian network model in segment \#2.

the principal component analysis described above, and the risk hazard value and total hazard value of each level were calculated by combining the hierarchical divisions of the fuzzy interpretive structural model.

$$
Q_{i}=q_{i} \times r_{i}
$$

...where $r_{i}$ is the degree of influence value of the risk indicator.

$$
L_{N}=\sum_{i=1}^{n} Q_{i}
$$

...where $n$ is the number of risk indicators contained in each level and $N$ is the level of hierarchy.

In the process of risk hazard analysis, according to the weight factor of each layer and the single risk factor impact value, it is convenient to study the risk hazard value of each layer, the relationship between 
Table 12. The grading of hazard levels.

\begin{tabular}{|c|c|c|}
\hline Hazard score & Levels description & Level \\
\hline$\geq 0.80$ & Very high & I \\
\hline $0.60-0.80$ & High & II \\
\hline $0.40-0.60$ & Medium & III \\
\hline $0.20-0.40$ & Low & IV \\
\hline$\leq 0.20$ & Very low & V \\
\hline
\end{tabular}

them and the impact on the total risk hazard value. Additionally, this approach is also conducive to on-site risk identification and control. According to the relevant literature and research on the risk and hazard degree of gas tunnels and actual projects, this paper establishes a quantitative classification standard of risk and hazard degree (Table 12).

In the process of gas tunnel construction, when the risk index is in a bad state, it may have a bad influence and cause a certain degree of harm to construction safety. In this paper, three experts scored the degree of damage caused by the safety risk indexes in segment \#1 and segment \#2 of the gas tunnel (Tables 13-14).

According to the above principal component analysis method, the weights of 12 risk indicators can be obtained (Table 15).

From the weights, the importance of each risk indicator in assessing the hazard level of gas tunnel construction is known.

The hazard value of each layer and the total hazard value are calculated (Tables 16-17).

In conclusion, the total hazard value of the safety risk in segment \#1 of the gas tunnel is grade II, and the total hazard value of the safety risk in segment \#2 of the gas tunnel is grade III.

\section{Assessment of Total Risk}

Due to different research focuses and objects, researchers have different definitions of risk, including "addition and sum" theory, "product" theory, and "single value" theory [45]. Among them, "product" theory includes the Australian dam commission's definition of risk as a measure of the probability

Table 13. Risk index hazard value of segment \#1.

\begin{tabular}{|c|c|c|c|c|c|c|c|c|c|}
\hline Risk indicators & \multicolumn{2}{|c|}{ Expert judgment } & Hazard value & Risk indicators & \multicolumn{2}{|c|}{ Expert judgment } & Hazard value \\
\hline Q1 & VH & H & H & 0.875 & Q7 & FL & M & FL & 0.433 \\
\hline Q2 & M & FL & M & 0.817 & Q8 & FH & FH & FH & 0.875 \\
\hline Q3 & H & FH & FH & 0.758 & Q9 & H & H & FH & 0.700 \\
\hline Q4 & H & H & VH & 0.817 & Q10 & FL & L & L & 0.367 \\
\hline Q5 & FH & M & M & 0.567 & Q11 & M & M & FL & 0.433 \\
\hline Q6 & VH & H & H & 0.817 & Q12 & FH & FH & M & 0.758 \\
\hline
\end{tabular}

Table 14. Risk index hazard value of segment \#2.

\begin{tabular}{|c|c|c|c|c|c|c|c|c|c|}
\hline Risk indicators & \multicolumn{2}{|c|}{ Expert judgment } & Hazard value & Risk indicators & \multicolumn{2}{|c|}{ Expert judgment } & Hazard value \\
\hline Q1 & H & M & M & 0.625 & Q7 & M & FL & FL & 0.433 \\
\hline Q2 & FL & FL & M & 0.367 & Q8 & FH & M & FH & 0.633 \\
\hline Q3 & FH & FH & M & 0.633 & Q9 & M & FH & FH & 0.758 \\
\hline Q4 & FL & FL & L & 0.242 & Q10 & FL & FL & L & 0.242 \\
\hline Q5 & M & M & FL & 0.433 & Q11 & M & M & FL & 0.433 \\
\hline Q6 & FH & FH & H & 0.758 & Q12 & FH & M & M & 0.567 \\
\hline
\end{tabular}

Table 15. Weight of risk indexes.

\begin{tabular}{|c|c|c|c|c|c|c|}
\hline \multirow{2}{*}{$q_{i}$} & $\mathrm{Q} 1$ & $\mathrm{Q} 2$ & $\mathrm{Q} 3$ & $\mathrm{Q} 4$ & $\mathrm{Q} 5$ & Q6 \\
\cline { 2 - 7 } & 0.131 & 0.176 & 0.100 & 0.037 & 0.069 & 0.182 \\
\hline \multirow{2}{*}{$q_{i}$} & $\mathrm{Q} 7$ & $\mathrm{Q} 8$ & $\mathrm{Q} 9$ & $\mathrm{Q} 10$ & $\mathrm{Q} 11$ & $\mathrm{Q} 12$ \\
\cline { 2 - 7 } & 0.057 & 0.069 & 0.115 & 0.018 & 0.026 & 0.020 \\
\hline
\end{tabular}


Table 16. FISM hazard value of each layer and total hazard value of segment \#1.

\begin{tabular}{|c|c|c|c|c|c|c|}
\hline Level & Level 1 & Level 2 & Level 3 & Level 4 & Level 5 & Total \\
\hline Hazard value & 0.151 & 0.292 & 0.256 & 0.040 & 0.011 & 0.750 \\
\hline
\end{tabular}

Table 17. FISM hazard value of each layer and total hazard value of segment \#2.

\begin{tabular}{|c|c|c|c|c|c|c|}
\hline Level & Level 1 & Level 2 & Level 3 & Level 4 & Level 5 & Total \\
\hline Hazard value & 0.095 & 0.203 & 0.224 & 0.036 & 0.011 & 0.569 \\
\hline
\end{tabular}

and severity of negative impacts on life, health and property environment and the product of the probability of dam failure and the consequences, that is the product of probability and consequence [46]. Based on comprehensive study of various risk theories and the reference of "product" theory, this paper aims to address the characteristics of gas tunnel construction, and the quantitative assessment of risk is carried out from two aspects, namely, risk probability $(\boldsymbol{P})$ and risk hazard degree assessment $(\boldsymbol{L})$. First, the randomness and complexity of gas and geological factors and the subjectivity and uncertainty of human factors are investigated. Second, each risk index will cause different degrees of harm when adverse changes occur. The gas tunnel risk assessment is carried out according to the following formula:

$$
\boldsymbol{R}=\boldsymbol{P} \times \boldsymbol{L}
$$

According to the comprehensive evaluation analysis and the actual construction of gas tunnels, the gas grading standard of gas tunnels is finally determined (Table 18).

\section{Results}

The results show that the total safety risk value of segment \#1 of this gas tunnel is 0.51 , the risk level is II, and the risk level is poor. The total safety risk value of segment \#2 of this gas tunnel is 0.17 , the risk level is V, and the risk level is good.
As the safety risk of segment \#1 is clearly higher than that of segment $\# 2$, the following risk assessment analysis is carried out for segment \#1 from the perspectives of risk probability and risk hazard degree.

For the risk probability, the risk probability in the unacceptable state is significantly higher than that in the acceptable state, and the risk probability evaluation grade of the gas tunnel is II. The risk indicators in Q8, Q2, and Q1. It is necessary to ensure the reliability of detection and monitoring equipment, which is the basis of providing accurate detection and monitoring data and plays a vital role in reducing gas concentration in the tunnel and taking further control measures. The possibility of gas tunnel construction risk is directly determined by the proper gas treatment method. Only scientific treatment schemes and efficient on-site treatment measures can ensure the safety of construction. The risk probability is set to $100 \%$ and backward reasoning is conducted to obtain the posterior probability of each node on the premise of the occurrence of risk accidents. Start from the $\mathrm{P}$ node to find the parent node with the maximum posterior probability. As shown in the figure, the most approximate factor chain of the fuzzy Bayesian network of gas tunnel risk probability is: $\mathrm{Q} 12 \rightarrow \mathrm{Q} 8 \rightarrow \mathrm{Q} 2 \rightarrow \mathrm{Q} 1 \rightarrow \mathrm{P}$ (Fig. 9) .

For the degree of risk hazard, the risk assessment degree of segment \#1 is II, indicating that the gas tunnel will cause greater harm once an accident occurs. In the explanation of the structural model level 2, the risk hazard value is relatively large. Q2 and Q6 once uncontrollable can easily cause large accident

Table 18. Total risk assessment criteria.

\begin{tabular}{|c|c|c|}
\hline The value of $\mathrm{R}$ & Levels description & Risk level \\
\hline$\geq 0.80$ & $\begin{array}{c}\text { The management level is very poor; the gas accumulation is serious in many areas; the gas } \\
\text { concentration seriously exceeds the warning value; the gas explosion or gas asphyxiation } \\
\text { accidents are easy to occur }\end{array}$ & I \\
\hline $0.50-0.80$ & $\begin{array}{c}\text { The management level is poor; gas accumulation occurs in many areas; gas concentration } \\
\text { exceeds the warning value; large area gas combustion accident is easy to occur }\end{array}$ & II \\
\hline $0.30-0.50$ & $\begin{array}{r}\text { The management level is few poor; the local gas accumulation occurs; the gas concentration } \\
\text { in the early warning value; the local gas combustion occurs occasionally }\end{array}$ & III \\
\hline $0.20-0.30$ & $\begin{array}{r}\text { The management level is medium; the gas accumulation phenomenon occurs occasionally; } \\
\text { the gas concentration is lower than the warning value }\end{array}$ & IV \\
\hline$\leq 0.20$ & The management level is good; the gas concentration is very low & V \\
\hline
\end{tabular}




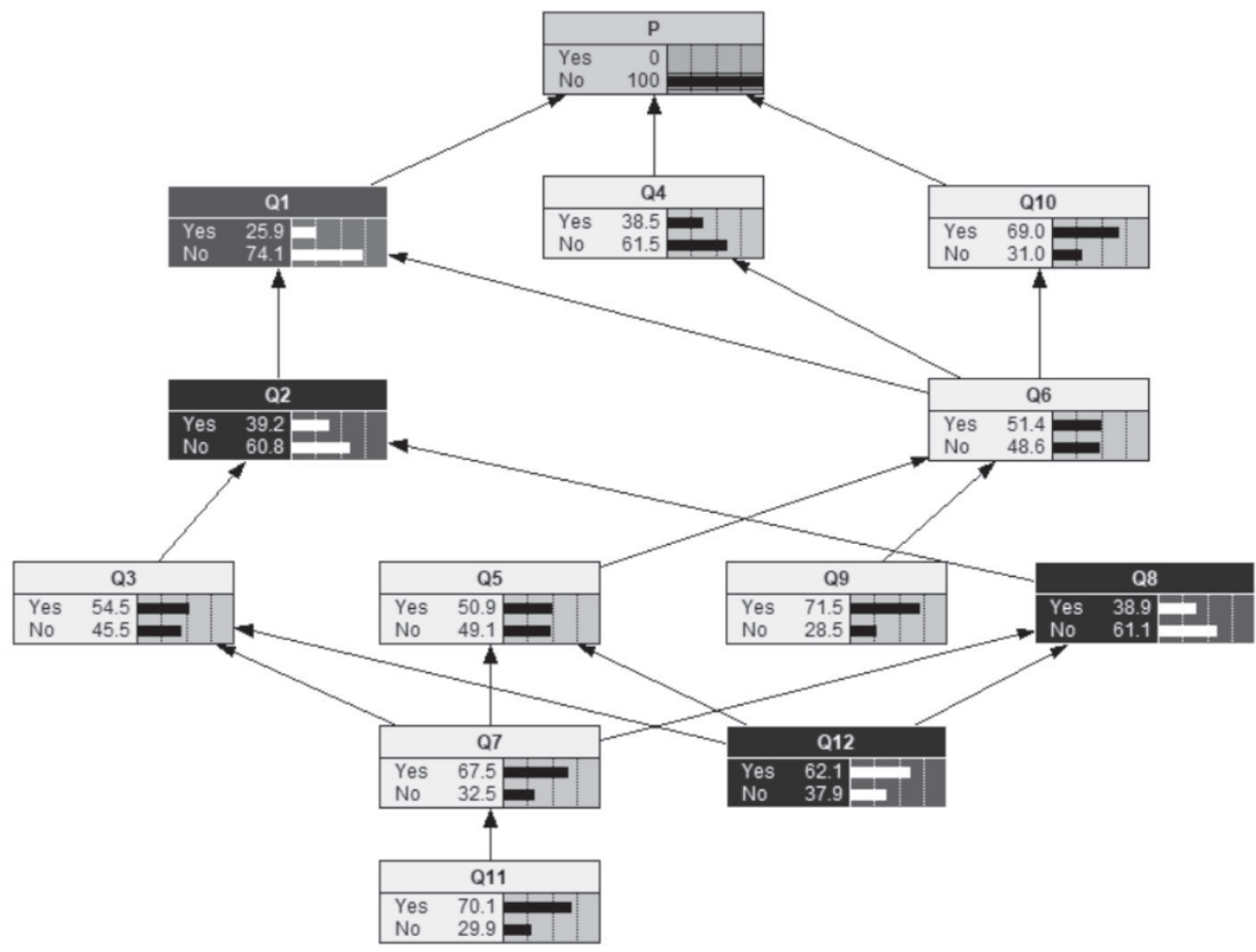

Fig. 9. Maximum causal chain.

consequences. Inaccurate data from detection and monitoring instruments will be seriously misleading for the subsequent processing, and the loss of control of gas emissions is more likely to cause serious disasters. In the interpretation of the structural model, the low level has a causal relationship with the high level, but it does not cause the accumulation of the degree of harm. The degree of hazard of the risk indicator is not directly related to the level of the structure.

Segment \#2 is a construction section after strengthening on-site construction management and gas control. In this segment, the risk probability and risk hazard degree are significantly lower than those of segment $\# 1$, and the total risk level is in a good condition. Therefore, to effectively reduce the safety risk of gas tunnels, it is necessary to implement an onsite construction management system into each process, strictly implement a gas management system and adopt a scientific and rational management method.

\section{Discussion}

1. In this paper, qualitative problems are transformed into quantitative problems by a subjective evaluation method, and multiple evaluation methods are applied together. Through "one blasting and three detections" and the gas concentration after ventilation in some key areas, the gas concentration in most areas is within a controllable range, but the gas concentration is relatively high in the areas where the gas easily accumulates, such as the arch on the tunnel face and the second lining trolley. According to the investigation of the construction situation, two gas-burning incidents occurred in the hot welding process of the tunnel, which verifies the accuracy of the evaluation system under the condition that the risk level of segment \#1 is poor. Relevant units must be reminded to strengthen the management and prevention in gas tunnel construction to avoid the occurrence of gas safety accidents.

2. The two construction sections selected in this paper have certain differences in construction management and gas management, which can achieve the effect of comparison and reference and verify the applicability and stability of the risk assessment model. The results of risk assessment show that the disaster risk can be effectively reduced by controlling the key risk nodes and improving the management and governance levels of the site.

3. Because the natural conditions and human factors of different construction sections of each gas tunnel or the same tunnel are different, the parameters of principal component analysis, the relationships between risk indicators in the FISM, and the values of prior probability and conditional probability in the FBN depend on the judgment of the construction site. An increase in the objective sample values can improve the accuracy of the above parameters.

4. In this paper, the risk hazard value is calculated from the perspective of structural hierarchy in the fuzzy interpretive structural model. The size and characteristics of the hazard value under the causal 
relationship are discussed. There is no correlation between the high-level risk index and the hazard value at the relatively low-level risk index. Therefore, it is not possible to reduce the control and prevention of a risk indicator because it belongs to a low-level hazard factor.

\section{Conclusions}

Gas tunnel construction involves various potential risks. Safety risk analysis and management of gas tunnel construction have aroused practitioners' attention. However, due to the special and dangerous construction environments and the serious lack of field data, it is difficult to accurately evaluate the safety risk of gas tunnels.

In existing research, some researchers have studied the risk assessment of gas tunnel construction through expert assessment and data analysis. However, there are differences in the selection of impact indicators, index classification, and evaluation methods. Through a large amount of literature review and data collection, this paper summarized and established a gas tunnel construction risk influencing factor system. This paper further establishes a fuzzy interpretive structural model according to the expert method and converts it into a fuzzy Bayesian network. The principal component analysis method is used to determine the weights of key indicators, and the fuzzy comprehensive evaluation method is used to combine the weights with the risk values to calculate the risk hazard degree value of the gas tunnel. Using the data obtained from a questionnaire survey to establish the fuzzy evaluation matrix, rather than directly determining the risk probability to evaluate the engineering risk, will be conducive to improving the accuracy and comprehensiveness of the risk assessment.

The risk analysis method of gas tunnel construction is applied to the Like tunnel to verify the feasibility and application prospects of this method. The proposed method can make management personnel comprehensively evaluate gas tunnel construction risk, reduce the risk in construction, and provide more scientific theoretical guidance for gas tunnel construction. Although the illustrative examples in this paper are based on the Like tunnel the proposed resiliency model is applicable for safety analysis of other gas tunnels, with the emphasis on the structure of the Bayesian network. To further improve the accuracy and reliability of the risk assessment, it is necessary to collect a large number of engineering cases and fieldmeasured data of gas tunnels. A more comprehensive and reliable safety accident database of gas tunnels can be established, and data mining and analysis can be conducted to improve the applicability of this method for risk assessment of different gas tunnels. In addition, the evaluation method can be developed into a system platform to establish a safety risk evaluation system of gas tunnel construction to provide a more timely, accurate and convenient evaluation process, which is of great significance to provide a safe construction environment.

\section{Appendix A}

Table A1. Expert assignment of the parent nodes of fuzzy Bayesian network.

\begin{tabular}{|c|c|c|c|c|c|c|c|c|c|c|c|c|}
\hline \multirow{3}{*}{$\begin{array}{c}\text { Node } \\
\text { Q11 }\end{array}$} & \multicolumn{6}{|c|}{$\# 1$} & \multicolumn{6}{|c|}{$\# 2$} \\
\hline & \multicolumn{3}{|c|}{$Y$} & \multicolumn{3}{|c|}{$N$} & \multicolumn{3}{|c|}{$Y$} & \multicolumn{3}{|c|}{$N$} \\
\hline & $\mathrm{M}$ & $\mathrm{M}$ & FL & FL & $\mathrm{L}$ & $\mathrm{L}$ & M & FL & FL & $\mathrm{L}$ & $\mathrm{L}$ & L \\
\hline Q12 & FH & FH & M & FL & FL & $\mathrm{M}$ & FH & FH & FH & $\mathrm{L}$ & FL & FL \\
\hline Q9 & $\mathrm{H}$ & $\mathrm{H}$ & FH & $\mathrm{M}$ & L & FL & $\mathrm{H}$ & $\mathrm{H}$ & FH & FL & $\mathrm{L}$ & FL \\
\hline
\end{tabular}

Table A2. Expert assignment of the child nodes of fuzzy Bayesian network.

\begin{tabular}{|c|c|c|c|c|c|c|c|c|c|c|c|c|c|}
\hline & & \multicolumn{6}{|c|}{$\# 1$} & \multicolumn{6}{|c|}{$\# 2$} \\
\hline Node & Q11 & \multicolumn{3}{|c|}{$Y$} & \multicolumn{3}{|c|}{$N$} & \multicolumn{3}{|c|}{$Y$} & \multicolumn{3}{|c|}{$N$} \\
\hline \multirow{2}{*}{ Q7 } & $Y$ & M & FL & FL & L & VL & $\mathrm{L}$ & FH & M & FH & L & VL & $\mathrm{L}$ \\
\hline & $N$ & $\mathrm{M}$ & M & FH & $\mathrm{H}$ & $\mathrm{H}$ & $\mathrm{H}$ & M & FH & FH & $\mathrm{M}$ & M & $\mathrm{M}$ \\
\hline
\end{tabular}


Table A3. Expert assignment of the child nodes of fuzzy Bayesian network.

\begin{tabular}{|c|c|c|c|c|c|c|c|c|c|c|c|c|c|c|}
\hline & & & \multicolumn{6}{|c|}{$\# 1$} & \multicolumn{6}{|c|}{$\# 2$} \\
\hline Node & Q7 & Q12 & \multicolumn{3}{|c|}{$Y$} & \multicolumn{3}{|c|}{$N$} & \multicolumn{3}{|c|}{$Y$} & \multicolumn{3}{|c|}{$N$} \\
\hline \multirow{4}{*}{ Q3 } & $Y$ & $Y$ & $\mathrm{H}$ & $\mathrm{M}$ & $\mathrm{H}$ & $\mathrm{L}$ & FL & $\mathrm{L}$ & $\mathrm{H}$ & $\mathrm{M}$ & $\mathrm{H}$ & $\mathrm{L}$ & L & $\mathrm{L}$ \\
\hline & $Y$ & $N$ & $\mathrm{M}$ & FL & FL & $\mathrm{H}$ & M & M & $\mathrm{M}$ & $\mathrm{M}$ & $\mathrm{FL}$ & FH & $\mathrm{M}$ & $\mathrm{M}$ \\
\hline & $N$ & $Y$ & $\mathrm{M}$ & $\mathrm{M}$ & FL & $\mathrm{M}$ & M & M & $\mathrm{M}$ & FH & $\mathrm{M}$ & $\mathrm{M}$ & $\mathrm{FL}$ & $\mathrm{M}$ \\
\hline & $N$ & $N$ & FL & $\mathrm{L}$ & $\mathrm{L}$ & $\mathrm{VH}$ & $\mathrm{VH}$ & $\mathrm{H}$ & FL & L & L & $\mathrm{H}$ & $\mathrm{H}$ & $\mathrm{H}$ \\
\hline Node & Q7 & Q12 & \multicolumn{3}{|c|}{$Y$} & \multicolumn{3}{|c|}{$N$} & \multicolumn{3}{|c|}{$Y$} & \multicolumn{3}{|c|}{$N$} \\
\hline \multirow{4}{*}{ Q5 } & $Y$ & $Y$ & $\mathrm{H}$ & $\mathrm{FH}$ & $\mathrm{H}$ & $\mathrm{M}$ & FL & FL & $\mathrm{H}$ & $\mathrm{H}$ & $\mathrm{H}$ & $\mathrm{M}$ & FL & $\mathrm{M}$ \\
\hline & $Y$ & $N$ & $\mathrm{M}$ & M & $\mathrm{FH}$ & $\mathrm{H}$ & $\mathrm{FH}$ & $\mathrm{H}$ & $\mathrm{H}$ & $\mathrm{FH}$ & $\mathrm{FH}$ & FL & M & M \\
\hline & $N$ & $Y$ & $\mathrm{M}$ & $\mathrm{M}$ & M & M & M & M & M & $\mathrm{FH}$ & M & M & FL & $\mathrm{M}$ \\
\hline & $N$ & $N$ & FL & FL & $\mathrm{L}$ & VH & $\mathrm{VH}$ & $\mathrm{VH}$ & FH & $\mathrm{FH}$ & $\mathrm{H}$ & M & FH & $\mathrm{M}$ \\
\hline Node & Q7 & Q12 & \multicolumn{3}{|c|}{$Y$} & \multicolumn{3}{|c|}{$N$} & \multicolumn{3}{|c|}{$Y$} & \multicolumn{3}{|c|}{$N$} \\
\hline \multirow{4}{*}{ Q8 } & $Y$ & $Y$ & $\mathrm{H}$ & $\mathrm{M}$ & M & M & FL & M & $\mathrm{H}$ & FH & M & M & M & FL \\
\hline & $Y$ & $N$ & FL & L & FL & VH & $\mathrm{H}$ & $\mathrm{H}$ & M & FL & FL & M & FH & FH \\
\hline & $N$ & $Y$ & $\mathrm{FH}$ & $\mathrm{M}$ & FL & $\mathrm{FH}$ & M & M & $\mathrm{FH}$ & M & M & M & FH & $\mathrm{M}$ \\
\hline & $N$ & $N$ & FL & L & L & VH & $\mathrm{VH}$ & $\mathrm{VH}$ & FL & FL & L & $\mathrm{H}$ & $\mathrm{H}$ & VH \\
\hline Node & Q3 & Q8 & \multicolumn{3}{|c|}{$Y$} & \multicolumn{3}{|c|}{$N$} & \multicolumn{3}{|c|}{$Y$} & \multicolumn{3}{|c|}{$N$} \\
\hline \multirow{4}{*}{ Q2 } & $Y$ & $Y$ & $\mathrm{H}$ & FH & $\mathrm{H}$ & M & $\mathrm{FL}$ & $\mathrm{FL}$ & $\mathrm{H}$ & $\mathrm{H}$ & $\mathrm{FH}$ & M & FL & FL \\
\hline & $Y$ & $N$ & FL & FL & $\mathrm{M}$ & $\mathrm{H}$ & $\mathrm{H}$ & $\mathrm{VH}$ & $\mathrm{FH}$ & FH & $\mathrm{FH}$ & FL & FL & M \\
\hline & $N$ & $Y$ & $\mathrm{M}$ & $\mathrm{M}$ & FH & $\mathrm{L}$ & VL & $\mathrm{L}$ & $\mathrm{M}$ & M & M & L & $\mathrm{L}$ & $\mathrm{L}$ \\
\hline & $N$ & $N$ & $\mathrm{~L}$ & FL & $\mathrm{L}$ & $\mathrm{VH}$ & $\mathrm{VH}$ & $\mathrm{VH}$ & $\mathrm{M}$ & M & $\mathrm{M}$ & FH & FH & FH \\
\hline Node & Q5 & Q9 & \multicolumn{3}{|c|}{$Y$} & \multicolumn{3}{|c|}{$N$} & \multicolumn{3}{|c|}{$Y$} & \multicolumn{3}{|c|}{$N$} \\
\hline & $Y$ & $Y$ & $\mathrm{FH}$ & $\mathrm{FH}$ & $\mathrm{H}$ & M & $\mathrm{M}$ & $\mathrm{FL}$ & FH & $\mathrm{H}$ & $\mathrm{FH}$ & M & FL & FL \\
\hline O6 & $Y$ & $N$ & FL & FL & $\mathrm{L}$ & VL & $\mathrm{L}$ & $\mathrm{L}$ & FL & M & $\mathrm{FL}$ & L & L & $\mathrm{L}$ \\
\hline & $N$ & $Y$ & M & M & FL & $\mathrm{FL}$ & $\mathrm{L}$ & FL & M & $\mathrm{FH}$ & M & FL & FL & FL \\
\hline & $N$ & $N$ & $\mathrm{~L}$ & $\mathrm{~L}$ & FL & VH & $\mathrm{H}$ & $\mathrm{VH}$ & $\mathrm{M}$ & $\mathrm{M}$ & $\mathrm{FL}$ & $\mathrm{H}$ & $\mathrm{H}$ & VH \\
\hline Node & Q2 & Q6 & & $Y$ & & & $N$ & & & $Y$ & & & $\Lambda$ & \\
\hline & $Y$ & $Y$ & $\mathrm{M}$ & $\mathrm{H}$ & FH & $\mathrm{M}$ & $\mathrm{FL}$ & FL & $\mathrm{M}$ & FH & $\mathrm{H}$ & $\mathrm{M}$ & FL & FL \\
\hline O1 & $Y$ & $N$ & $\mathrm{M}$ & FL & FL & $\mathrm{FH}$ & $\mathrm{FH}$ & $\mathrm{M}$ & $\mathrm{M}$ & FH & $\mathrm{FH}$ & FL & FL & $\mathrm{M}$ \\
\hline & $N$ & $Y$ & $\mathrm{M}$ & $\mathrm{M}$ & $\mathrm{M}$ & $\mathrm{M}$ & $\mathrm{M}$ & $\mathrm{FH}$ & $\mathrm{M}$ & FH & $\mathrm{FH}$ & $\mathrm{M}$ & M & $\mathrm{M}$ \\
\hline & $N$ & $N$ & $\mathrm{~L}$ & FL & FL & $\mathrm{H}$ & $\mathrm{H}$ & $\mathrm{VH}$ & FH & $\mathrm{FH}$ & $\mathrm{M}$ & FL & FL & $\mathrm{M}$ \\
\hline
\end{tabular}

Table A4. Expert assignment of the child nodes of fuzzy Bayesian network.

\begin{tabular}{|c|c|c|c|c|c|c|c|c|c|c|c|c|c|}
\hline & & \multicolumn{6}{|c|}{$\# 1$} & \multicolumn{6}{|c|}{$\# 2$} \\
\hline Node & Q6 & \multicolumn{3}{|c|}{$Y$} & \multicolumn{3}{|c|}{$N$} & \multicolumn{3}{|c|}{$Y$} & \multicolumn{3}{|c|}{$N$} \\
\hline \multirow{2}{*}{ Q4 } & $Y$ & $\mathrm{H}$ & $\mathrm{FH}$ & FH & $\mathrm{M}$ & FL & M & VH & VH & $\mathrm{H}$ & VL & VL & L \\
\hline & $N$ & M & FL & FL & FH & FH & $\mathrm{FH}$ & FH & $\mathrm{H}$ & $\mathrm{H}$ & FL & FL & FL \\
\hline Node & Q6 & \multicolumn{3}{|c|}{$Y$} & \multicolumn{3}{|c|}{$N$} & \multicolumn{3}{|c|}{$Y$} & \multicolumn{3}{|c|}{$N$} \\
\hline \multirow{2}{*}{ Q10 } & $Y$ & $\mathrm{H}$ & VH & $\mathrm{H}$ & $\mathrm{L}$ & VL & L & $\mathrm{H}$ & VH & $\mathrm{VH}$ & $\mathrm{L}$ & $\mathrm{L}$ & L \\
\hline & $N$ & $\mathrm{M}$ & FH & FH & FH & M & $\mathrm{M}$ & M & $\mathrm{H}$ & FH & $\mathrm{M}$ & M & $\mathrm{M}$ \\
\hline
\end{tabular}


Table A5. Expert assignment of the child nodes of fuzzy Bayesian network.

\begin{tabular}{|c|c|c|c|c|c|c|c|c|c|c|c|c|c|c|c|}
\hline \multirow[b]{2}{*}{ Node } & \multirow[b]{2}{*}{ Q1 } & \multirow[b]{2}{*}{ Q4 } & \multirow[b]{2}{*}{ Q10 } & \multicolumn{6}{|c|}{$\# 1$} & \multicolumn{6}{|c|}{$\# 2$} \\
\hline & & & & \multicolumn{3}{|c|}{$Y$} & \multicolumn{3}{|c|}{$N$} & \multicolumn{3}{|c|}{$Y$} & \multicolumn{3}{|c|}{$N$} \\
\hline \multirow{8}{*}{$\mathrm{P}$} & $Y$ & $Y$ & $Y$ & $\mathrm{VH}$ & $\mathrm{H}$ & $\mathrm{H}$ & VL & VL & $\mathrm{L}$ & $\mathrm{H}$ & $\mathrm{H}$ & $\mathrm{VH}$ & VL & $\mathrm{L}$ & VL \\
\hline & $Y$ & $Y$ & $N$ & $\mathrm{M}$ & $\mathrm{M}$ & M & $\mathrm{M}$ & FH & $\mathrm{M}$ & M & FH & M & $\mathrm{M}$ & $\mathrm{M}$ & $\mathrm{M}$ \\
\hline & $Y$ & $N$ & $N$ & $\mathrm{~L}$ & FL & FL & $\mathrm{M}$ & FH & $\mathrm{FH}$ & FL & M & FL & $\mathrm{M}$ & $\mathrm{M}$ & FH \\
\hline & $Y$ & $N$ & $N$ & $\mathrm{~L}$ & $\mathrm{~L}$ & FL & $\mathrm{FH}$ & FH & $\mathrm{FH}$ & FL & $\mathrm{M}$ & $\mathrm{M}$ & $\mathrm{M}$ & FL & FL \\
\hline & $N$ & $Y$ & $Y$ & $\mathrm{~L}$ & FL & $\mathrm{L}$ & FH & $\mathrm{H}$ & $\mathrm{FH}$ & $\mathrm{FH}$ & FH & FH & $\mathrm{M}$ & $\mathrm{M}$ & FH \\
\hline & $N$ & $Y$ & $N$ & $\mathrm{~L}$ & $\mathrm{~L}$ & $\mathrm{~L}$ & FH & $\mathrm{H}$ & $\mathrm{H}$ & M & $\mathrm{M}$ & FL & $\mathrm{M}$ & M & FH \\
\hline & $N$ & $N$ & $Y$ & $\mathrm{~L}$ & $\mathrm{~L}$ & VL & $\mathrm{H}$ & $\mathrm{H}$ & $\mathrm{H}$ & $\mathrm{M}$ & FL & $\mathrm{M}$ & M & M & M \\
\hline & $N$ & $N$ & $N$ & VL & $\mathrm{L}$ & VL & $\mathrm{VH}$ & $\mathrm{VH}$ & $\mathrm{H}$ & FL & M & FL & $\mathrm{H}$ & FH & $\mathrm{H}$ \\
\hline
\end{tabular}

\section{Acknowledgments}

Much of the work presented in this paper was supported by the National Natural Science Foundations of China (grant numbers 41877239, 51379112, 51422904 and 41772298), Key Technology Research and Development Program of Shandong Province (grant number 2019GSF111028) and the Fundamental Research Funds of Shandong University (2018JC044). The authors would like to express appreciation to the reviewers for their valuable comments and suggestions that helped improve the quality of our paper.

\section{Conflict of Interest}

The authors declare no conflict of interest.

\section{References}

1. KANG X.B., LUO S., LI Q.S., XU M. LI Q. Developing a risk assessment system for gas tunnel disasters in China. Journal of Mountain Science, 14 (9),1751, 2017.

2. COPUR H., CINAR M., OKTEN G., BIlGIN N. A case study on the methane explosion in the excavation chamber of an EPB-TBM and lessons learnt including some recent accidents. Tunnelling and Underground Space Technology, 27, 159. 2012.

3. HE S.Y., SU L.J., FAN H.B., REN R. Methane explosion accidents of tunnels in SW China. Geomatics, Natural Hazards and Risk, 10 (1),667, 2019.

4. DOYLE, B., 2001.Hazardous Gases Underground. Marcel Dekker, New York.

5. KUANG L., ZHANG J.Y., ZHANG Q. Research on the classification method of railway gas tunnel. Journal of Railway Engineering Society, 34 (8),73, 2017 [In Chinese].

6. MENG X.F., LIU Q.L., LUO, X.X., ZHOU X.X. Risk assessment of the unsafe behaviours of humans in fatal gas explosion accidents in China's underground coal mines. Journal of Cleaner Production, 210, 970, 2019.

7. ZHANG K., ZHENG W.B., XU C., CHEN S.G. Risk assessment of gas outburst in tunnels in non-coal formation based on the attribute mathematical theory. Geomatics, Natural Hazards and Risk, 10(1),483, 2019.

8. WANG Q.X., WANG H., QI Z.Q. An application of nonlinear fuzzy analytic hierarchy process in safety evaluation of coal mine. Safety Science, 86,78, 2016.

9. FEN X.D., JIMENEZ R. Predicting tunnel squeezing with incomplete data using Bayesian networks. Engineering Geology, 195, 214, 2015.

10. WANG Z.Z., CHEN C. Fuzzy comprehensive Bayesian network-based safety risk assessment for metro construction projects. Tunnelling and Underground Space Technology, 70, 330, 2017.

11. TONG X., FANG W.P., YUAN S.Q., MA J.Y., BAI Y.P. Application of Bayesian approach to the assessment of mine gas explosion. Journal of Loss Prevention in the Process Industries, 54, 238, 2018.

12. ZAREI E., KHAKZAD N., COZZANI V., RENIERS G. Safety analysis of process systems using Fuzzy Bayesian Network (FBN). Journal of Loss Prevention in the Process Industries, 57, 7, 2019.

13. ZHANG L.M., WU X.G., QIN Y.W., SKIBNIEWSKI M.J., LIU W.L. Towards a fuzzy Bayesian network based approach for safety risk analysis of tunnel-induced pipeline damage. Risk Analysis, 36 (2), 278, 2016.

14. SUN J.L., LIU B.G., CHU Z.F., CHEN L., LI X. Tunnel collapse risk assessment based on multistate fuzzy Bayesian networks. Quality and Reliability Engineering International, 34 (8), 1646, 2018.

15. ZHANG Y., WANG C., WEI M.Y., CHEN P. Study on risk assessment of methane gas explosion in mine heading face based on fault tree analysis. Coal Technology, 29 (11), 70, 2010 [In Chinese].

16. NIAN Q.F., SHI S.L., LI R.Q. Research and application of safety assessment method of gas explosion accident in coal mine based on GRA-ANP-FCE. Procedia Engineering, 45 (2), 106, 2012.

17. CHENG J.W., LUO Y., ZHOU F.B. Explosibility safety factor: an approach to assess mine gas explosion risk. Fire Technology, 51 (2), 309, 2015.

18. SHI S.L., JIANG B.Y., MENG X.R. Assessment of gas and dust explosion in coal mines by means of fuzzy fault tree analysis. International Journal of Mining Science and Technology, 28 (6), 991, 2018.

19. WILSON R., CROUCH E.A. Risk assessment and comparisons: an introduction. Science, 236 (4799), 267, 1987. 
20. MASKTEY A. Disaster mitigation: a community based approach. Oxford, England, Oxfam, 1989.

21. EINSTEIN H.H. Risk and risk analysis in rock engineering. Tunnelling and Underground Space Technology, 11 (2), 141, 1996.

22. ESKESEN S.D., TENGBORG P., KAMPMANN J., VEICHERTS T.H. Guidelines for tunneling risk management: International Tunnelling Association, Working Group No.2. Tunnelling and Underground Space Technology, 19 (3), 217, 2004.

23. ZHANG X.L., XUE Y.G., QIU D.H., YANG W.M. SU M.X., LI Z.Q., ZHOU B.H. Multi-Index Classification Model for Loess Deposits Based on Rough Set and BP Neural Network. Polish Journal of Environmental Studies 28 (2), 953, 2019.

24. WANG X.T., LI S.C., MA X.Y., XUE Y.G., HU J., LI Z.Q. Risk Assessment of Rockfall Hazards in a Tunnel Portal Section Based on Normal Cloud Model. Polish Journal of Environmental Studies, 26 (5), 2295, 2017.

25. WANG Y.C., OLGUN C. G., WANG L.B., MENG B., Risk Assessment of Water Inrush in Karst Tunnels Based on the Ideal Point Method. Polish Journal of Environmental Studies, 28 (2), 901, 2019.

26. ILBAHAR E., KARAŞAN A., CEBI S., KAHRAMAN C. A novel approach to risk assessment for occupational health and safety using Pythagorean fuzzy AHP \& fuzzy inference system. Safety Science, 103, 124, 2018.

27. BROWN E.T. Risk assessment and management in underground rock engineering - an overview. Journal of Rock Mechanics and Geotechnical Engineering, 4 (3), 193, 2012.

28. NÝVLT O., PRIVARA S., FERKL L. Probabilistic risk assessment of highway tunnels. Tunnelling and Underground Space Technology, 26 (1), 71, 2011.

29. JOLLIFFE I.T. Principal component analysis, second ed. Springer, New York, 2002.

30. WOLD S., ESBENSEN K., GELADI P. Principal Component Analysis. Chemometrics and Intelligent Laboratory Systems, 2 (1-3), 37, 1987.

31. WARFILD J.N. Participative methodology for public system planning. Computers \& Electrical Engineering, 1 (2), 187, 1973.
32. ZADEH L. A. Fuzzy Sets. Information and control 8, 338, 1965.

33. CHEN S.J., HWANG C.L. Fuzzy multiple attribute decision making. Springer, Berlin Heidelberg, 1992.

34. HUANG L., CAI C.L. Fuzzy interpretive structural model. Journal of Sichuan University (Natural Science Edition). 1, 6, 1999 [In Chinese].

35. YE J.M., XU, Z.S., GOU X.J. A new perspective of Bayes formula Based on D-S theory in interval intuitionistic fuzzy environment and its applications. International Journal of Fuzzy Systems, 21 (4), 1196, 2019.

36. HECKERMAN D., WELLMAN M.P. Bayesian networks. Communication of the ACM, 38 (3), 27, 1995.

37. JENSEN F.V., NIELSEN T.D. Bayesian Networks and Decision Graphs, second ed. Springer, New York, 2007.

38. JENSEN F.V. An Introduction to Bayesian Networks, UCL Press, London, 1996.

39. NADKARNI S., SHENOY P.P. A causal mapping approach to constructing Bayesian networks. Decision Support Systems. 38 (2), 259, 2004.

40. QIU C.H., CHEN S.G., TAN X.R., HUO X.L. Construction risk assessment for gas tunnels based on fuzzy analytic hierarchy process. Chinese Journal of Underground Space and Engineering, 11 (03), 774, 2015 [In Chinese].

41. PALLANT J. The SPSS Survival Guide. fifth ed. McGrawHill Higher Education, 2013.

42. RAMZALI N., LAVASANI M.R.M., GHODOUSI J. Safety barriers analysis of offshore drilling system by employing Fuzzy Event Tree Analysis. Safety Science, 78, 49, 2015.

43. WANG J., CAO Y. Optimizing Passenger Traffic Structure Based on a Fuzzy Interpretive Structure Model. Journal of Transport Information Safety, 35 (4), 112, 2017 [In Chinese].

44. Norsys Software Corporation. Netica Application User's Guide. Norsys Software Corporation, Vancouver, BC, Canada, 1998.

45. MA B.C. Definition and Expression Methods for Natural Disaster Risk. Journal of Catastrophology, 30 (3), 16, 2015 [In Chinese].

46. ANCOLD. Guidelines on Risk Assessment. Tatura: Australian National Committee on Large Dams, 24, 2003. 